\title{
RATE OF OXIDATION OF TYPICAL NONFERROUS METALS AS DETERMINED BY INTERFERENCE COLORS OF OXIDE FILMS
}

\author{
By Dunlap J. McAdam, Jr. and Glenn W. Geil
}

\begin{abstract}
By means of interference colors the rates of oxidation were determined for 18 nonferrous metals and were compared with those for typical steels. The influence of temperature, oxidation time, and film thickness on the rate of oxidation is illustrated by projections of surface in three-dimensional diagrams. The diagrams for the nonferrous metals are similar to those for steels. For a constant film thickness, the relation between temperature and oxidation time is linear logarithmic. The variation of film thickness with either temperature or oxidation time, plotted logarithmically, is represented by a reversed curve. A discussion is given of the influence of the affinity of the metal for oxygen and of the rate of diffusion through the oxide film. The film behaves as if the specific resistance varies nonlinearly with the film thickness.
\end{abstract}

\section{CONTENTS}

I. Introduction _...

II. Electrochemical theory of the dry oxidation of metals.

III. Materials and method _... 596

IV. Influence of temperature on oxidation time for constant film thickness _ 597

1. General description of diagrams_.................. 597

2. Diagrams for typical metals _._. _._._.

3. Relative positions of the diagrams for typical nonferrous metals and three typical steels _..._...

V. Variation of the film thickness with time at constant temperature _.. 599

1. Derivation of diagrams _....... 599

2. General description of the diagrams_.............. 600

3. Form of the curve of variation of film thickness with time at constant temperature

VI. Variation of the film thickness with temperature, for constant oxidation time. . . . .

1. General description of diagrams

2. Form of the curves of variation of film thickness with temperature, for constant oxidation time

VII. Factors affecting the form and position of the three-dimensional diagram representing the oxidation of a metal _...

1. Influence of the affinity of the metal for oxygen on the rate of diffusion through the oxide film _.................. 604

2. Influence of the affinity of the metal for oxygen on the initial rate of oxidation

3. Reasons for the complex variation of the rate of oxidation with the film thickness_........

VIII. Summary

IX. References 


\section{INTRODUCTION}

In a previous paper [10], ${ }^{1}$ the authors gave results of an investigation of the rate of formation of oxide films on steels at elevated temperatures. The thickness of these films was determined by means of interference colors, sometimes called "temper" colors or "heat" colors. These colors are caused by interference between rays of light reflected from the inner and outer surfaces of the oxide film. The coincidence of two waves differing in phase by $180^{\circ}$ causes light of a certain wavelength to disappear; if the incident light is heterogeneous, therefore, the reflected light is of the corresponding complementary color. Interference occurs when the film thickness is an odd multiple of one-fourth the wavelength of a component of the incident light. Interference, however, is determined by the wavelength in the film, not by the wavelength in air. The index of refraction of the oxide, therefore, is a factor involved in the relations between wavelength, film thickness, and interference color. A knowledge of the wavelength of the light in the oxide film, corresponding to an interference color, would make it possible to estimate the film thickness.

By means of interference colors caused by oxide films, a study has been made of the rate of oxidation of typical nonferrous metals, as affected by composition, temperature, oxidation time, and film thickness. In this paper, as in the previous paper, two-dimensional diagrams of three types are presented as complementary views of three-dimensional diagrams, each showing the relation between temperature, oxidation time, and film thickness. The first type shows the relation between temperature and oxidation time, for constant interference colors (constant film thickness). The second type shows the relation between oxidation time and film thickness, for several constant temperatures. The third type shows the relation between temperature and film thickness, for constant oxidation time.

Figures of assembled graphs representing the nonferrous metals and typical steels are also presented. These diagrams show the relative resistance of these metals to oxidation and are used in a study of the relation between resistance to oxidation and the properties of the oxide film.

\section{ELECTROCHEMICAL THEORY OF THE DRY OXI- DATION OF METALS}

A general résumé of the literature on the oxidation of metals has already been given [10], together with brief mention of the prevalent theories. A more detailed outline will now be given of the electrochemical theory of oxidation, based chiefly on the investigations of Wagner and his coworkers [1, 2, 3, 4, 18, 19, and 20].

This theory states that after the first adherent film of oxide has formed the reaction proceeds by movement of ions and electrons through the film. The film consists of a space lattice of electropositive metal ions and electronegative oxygen ions. During oxidation, metal ions and an equivalent number of electrons leave the metal, enter the film, and move outward toward the film-gas interface. The oxygen ions in the film, however, are too large to diffuse inward, because each oxygen atom has acquired two electrons on taking its place

1 Figures in brackets indicate the literature references at the end of this paper. 
in the film. The growth of the film, therefore, consists chiefly in the meeting of oxygen ions and outwardly diffused metal ions at the filmgas interface.

The elements in a metal oxide may not be in the stoichiometric proportions. In the oxides of zinc and cadmium (and possibly aluminum at very high temperatures), the metal is in slight excess. In $\mathrm{FeO}$, $\mathrm{Cu}_{2} \mathrm{O}$, and $\mathrm{NiO}$, oxygen is said to be in slight excess [3, 4], although there is a contrary report for $\mathrm{Cu}_{2} \mathrm{O}$ [8]. Such an excess of oxygen is said to be characteristic of the lower oxides of metals; in $\mathrm{CuO}$ and in other higher oxides of metals, the elements are said to be in stoichiometric proportions.

In $\mathrm{ZnO}$, and possibly in other oxides that have excess of metal, the excess ions of metal are believed to be in the interstices of the lattice, and are accompanied by an equivalent number of free electrons. In the oxidation of such a metal, the metal ions and electrons move outward through the interstices of the lattice. When the oxide has a slight deficiency of metal (as in $\mathrm{FeO}$ ), however, some of the positions generally occupied by metal ions in the space lattice are vacant. The outward movement of metal ions through such an oxide consists of jumps of ions from occupied to unoccupied positions in the lattice. Even in some oxides that are of stoichiometric composition, there are said to be vacancies in the metal space lattice and an equivalent number of metal ions in the interstices of the lattice.

The outward movement of electrons, moreover, may consist in either the outward flow of quasi-free electrons or a series of jumps from occupied positions to electron vacancies, sometimes called positive holes. In $\mathrm{Cu}_{2} \mathrm{O}$, for example, nearly all the copper ions have one less electron than a copper atom. A few ions, however, have lost two electrons and thus are cupric ions. As the electrons move outward by jumps, the positions of these positive holes move inward until they are filled at the metal-oxide interface.

According to the theory, therefore, the process of diffusion of ions and electrons varies greatly with the composition of the oxide film. These variations probably are associated with considerable differences of the rate of diffusion, and hence with considerable differences of the rate of oxidation. Unfortunately for the application of this theory, however, detailed information about the diffusion process is available for only a few metal oxides, and some of even this meager information (as reported by different investigators) is contradictory.

The total process of oxidation of a metal consists in three individual processes [14]: (a) Transfer of metal across the metal-film interface; (b) diffusion of metal ions and electrons outward through the film; and (c) adsorption of oxygen at the film-gas interface, and transfer across the interface. The rate of oxidation is controlled by the process which is naturally the slowest of the three. Initially process (a) is the controlling factor, and for a while the rate of oxidation is practically independent of the partial pressure of the oxygen and of the film thickness. Process (c) may control when the oxygen pressure is very low. With increase in the film thickness, process (b) becomes increasingly important, and eventually the controlling factor is the rate of diffusion through the film.

As shown by Price [14], the system comprising metal, film, and oxygen may be viewed as a galvanic cell, whose electrodes are the metal and the oxygen gas. In this cell, the film substance acts both 
as the electrolyte and as the external circuit. In its ionic conduction, the film plays the role of the electrolyte; in its electronic conduction, the film plays the role of the external circuit of a galvanic cell. The electromotive force of this cell is provided by the affinity of the metal for oxygen. If $n_{1}, n_{2}$, and $n_{3}\left(n_{1}+n_{2}+n_{3}=1\right)$ are the transport numbers of cations, anions, and electrons, respectively, the part of the total electromotive force $E$, required to drive electrons through the film is $\left(n_{1}+n_{2}\right) E$, and the part required to drive ions through the film is $n_{3} E$. For oxidation of metals, $n_{2}$ is negligible and $n_{1}$ is generally small in relation to $n_{3}$. Most of the energy, therefore, is expended in movement of the ions.

\section{MATERIALS AND METHOD}

The materials used in this investigation were as follows: electrolytic copper, lead, and zinc, aluminum of about 99.9 percent purity, and nickel of the commercial $A$ grade. A typical percentage composition of the nickel is: $\mathrm{Ni}+\mathrm{Co}, 99.40 ; \mathrm{C}, 0.10 ; \mathrm{Si}, 0.05 ; \mathrm{S}, 0.005$; $\mathrm{Cu}, 0.10 ; \mathrm{Fe}, 0.15 ; \mathrm{Mn}, 0.20$. Ruthenium and rhodium (99.99 percent pure) were prepared at this Bureau. Cadmium, chromium, cobalt, columbium, manganese, silicon, tantalum, tungsten, vanadium, and zirconium were purchased as "pure" metals from A. D. Mackay, New York City.

The method of preparing the specimens for the investigations and the method of experiment were the same as that used for steels, as described in the previous paper [10]. Suitable specimens of each metal were prepared and one surface was polished and cleaned. The specimens, with polished surface upward, were placed in a small electric furnace which was automatically maintained within 0.5 percent of the desired absolute temperature. The oxidation time was counted as beginning with the insertion of the specimen into the furnace, with no allowance for the time required to heat the specimen to the temperature of the furnace, or for the effect of the brief lowering of the temperature each time the furnace was partly opened to facilitate observation of the colors. From previous work [10], however, it is known that such allowances are important for short oxidation times but usually unimportant for oxidation times greater than about 20 minutes.

The oxidation times were observed for the appearance of the most easily distinguishable of the interference colors - straw, brown, and blue. It was usually possible to observe the first- and second-order colors. For some metals the third-order brown and blue and even the fourth-order blue were observed. Complete diagrams representing the relation between temperature, oxidation time, and film thickness were obtained with eight of these metals: copper, lead, nickel, ruthenium, silicon, tungsten, vanadium, and zinc. Although only incomplete diagrams were obtained with the other metals, the diagrams (not shown) have been established well enough to indicate the approximate relative positions of the graphs representing firstorder blue. 


\section{INFLUENCE OF TEMPERATURE ON OXIDATION TIME FOR CONSTANT FILM THICKNESS}

\section{GENERAL DESCRIPTION OF DIAGRAMS}

In studying the relation between temperature, time, and film thickness, consideration will be given first to the relation between temperature and time, for constant film thickness (constant interference color). Diagrams representing this relation for typical nonferrous metals are shown in figures 1 to 5 .

Logarithmic coordinates are used in these diagrams. Abscissas represent oxidation time in minutes; at the top of each figure is an additional scale representing days. Ordinates, as in the previous paper [10], represent the tenth power of the absolute temperature; the slope (tangent of the angle) thus has been multiplied by 10. Each figure also contains a scale in degrees centigrade.

The graphs ${ }^{2}$ in these figures represent the temperature-time relation for straw color, reddish brown, and blue, of the first and higher orders. Each graph is designated by a letter $(X, Y$, or $Z)$ representing straw color, reddish brown, or blue, respectively. For colors of the second, third, or fourth order, this letter is followed by a numeral designating the order.

The solid-line graphs in figures 1 to 5 are based on the uncorrected positions of the experimental points. Each line is based not only on the experimental points belonging to that line, but also on the probable ideal relationship (in form and position) between all the lines of the diagram. In determining the form of such a diagram, moreover, consideration was given to the complementary diagrams of the two other types, discussed in sections V and VI. Each diagram of the type shown in figures 1 to 5 thus represents a plan view of a surface in a three-dimensional diagram.

\section{DIAGRAMS FOR TYPICAL METALS}

In figures 1 to 5 , the solid lines representing the various interference colors are straight throughout most of their extent, but are curved throughout the portions representing short oxidation time. Correction to allow for the time required to heat the specimen to the temperature of the furnace, or for the brief decrease of temperature whenever the furnace was partly opened, probably would make the graphs straight throughout their entire extent, as indicated by the broken lines diverging from some of the solid lines. The graphs for these nonferrous metals, therefore, are similar to the graphs for steels, presented in the previous paper [10].

In figure 3 the diagrams for zinc and lead are plotted with the same coordinate scales. In figures 4 and 5 the two diagrams are plotted with the same abscissa scale, but with different ordinate scales, indicated at the left and right sides of the figure.

In the diagrams (figs. $1,2,3$, and 5) for nickel, tungsten, zinc, ${ }^{3}$ vanadium, and ruthenium, the slope of a graph varies with the interference color; the slope is greatest for the lowest line in each diagram

\footnotetext{
"The word "graph" is used to designate a single straight line or curve and the points on which it is based; the word "diagram" is used to designate a series or family of graphs.

3 Vernon [17] was unable to obtain interference colors with zinc.
} 
and is least for the highest line. The slope evidently decreases with increase in the corresponding film thickness. The difference in slope between two adjacent lines is greatest for straw color and reddish brown of the first order, and becomes less as the film thickness increases. These diagrams, therefore, are qualitatively similar to the diagrams for nearly all of the steels represented in the previous paper [10]. The diagrams for a few of the alloy steels show very little difference in slope between the lowest and highest lines. Similar to these are the diagrams for lead, silicon, and copper shown in figures 3 and 4 of the present paper.

The linear relation represented by the corrected graphs, as shown in the previous paper, may be represented by the equation

$$
t_{2} / t_{1}=\left(T_{1} / T_{2}\right)^{n}
$$

In this equation, $t$ represents the oxidation time, $T$ represents the absolute temperature, and $n$ represents the reciprocal of the slope, allowance being made for the fact that the slope in these figures has been multiplied by 10 . Equation 1, therefore, indicates that the oxidation time (for constant film thickness) varies inversely as the $n$th power of the absolute temperature, and that the mean rate of oxidation (the reciprocal of the oxidation time) varies directly as the same power of the temperature. Values of $n$ for all the graphs shown in figures 1 to 5 and for three typical steels are listed in table 1 .

In addition to the diagrams shown in figures 1 to 5 , incomplete diagrams have been obtained for aluminum, cadmium, chromium, cobalt, columbium, manganese, molybdenum, rhodium, tantalum, and zirconium. For aluminum, cadmium, and rhodium, only the position of each line has been established; for the others, both the form and the position have been established. These diagrams are similar in form to those in figures 1 to 5 . Lines for first-order blue for these metals have been assembled in figure 8 .

\section{RELATIVE POSITIONS OF THE DIAGRAMS FOR TYPICAL NON- FERROUS METALS AND THREE TYPICAL STEELS}

A qualitative study of the relative resistances to oxidation of the nonferrous metals and the typical steels may be made by comparing the graphs for the same interference color. Such a comparison is made in figures 6 to 9 ; the interference colors represented in these figures are the three first-order colors and third-order blue. The steels used in this comparison are electrolytic iron, 13.6-percent chromium steel, and 24.4-percents chromium steel. As shown in the previous paper [10], the diagrams for carbon steels and for steels containing no more than 3 percent of chromium differ little in position from the diagram for electrolytic iron.

In the diagram representing straw color (fig. 6), the lines representing silicon and ruthenium are far above the other lines, including the lines representing the two stainless steels. The lines for nickel, tungsten, and 24.4-percent chromium steel differ little in position. Not far below these are the lines for zinc, vanadium, and 13.5 percent chromium steel. Although lead and copper are less corrodible than iron when in contact with water, they evidently are much inferior to iron in resistance to oxidation at elevated temperatures in air. In the 
diagram representing first-order brown (fig. 7), the lines for nickel, tungsten, and zinc are somewhat higher in relation to the lines for silicon, ruthenium, lead, and copper than they are in figure 6 , and the lines for the two stainless steels (especially the 24.4-percent chromium steel) are much higher in relation to the lines for all the other metals.

In the diagram representing first-order blue (fig. 8), continuous lines are used to represent the graphs completely established, broken lines are used for the graphs whose form and position have been approximately established, and dotted lines are used for the graphs whose approximate positions alone have been established. The line for the 13.6-percent chromium steel is relatively much higher than in figure 7 , and now nearly coincides with the lines for ruthenium, chromium, and 24.4-percent chromium steel. The relative positions of the other continuous lines (from graphs completely established) have changed little. In the diagram representing third-order blue (fig. 9), the relative position of the line for 24.4-percent chromium steel has improved slightly, and the relative positions of the other lines are practically unchanged. With increase in the film thickness, therefore, the most striking improvement in relative resistance to oxidation was obtained with the two stainless steels. Nickel, tungsten, zinc, and vanadium, however, improved somewhat. The greatest change in the relative positions of the lines occurred between the film thicknesses corresponding to straw color and brown of the first order.

\section{VARIATION OF THE FILM THICKNESS WITH TIME AT CONSTANT TEMPERATURE}

\section{DERIVATION OF DIAGRAMS}

Each diagram of figures 1 to 5 represents a plan view of a surface as seen in a three-dimensional diagram in which the vertical dimension (normal to the plane of the figure) represents film thickness. The graphs in each of these diagrams, therefore, may be viewed as contour lines. Because the film thickness corresponding to a contour line increases with the progression of the interference colors, a plan view gives qualitative information about the form of the surface in the three-dimensional diagram. For more definite information, both qualitative and quantitative, it is necessary to consider not only the plan view, but also the front view and the side elevation. The front view gives direct information about the variation of the film thickness with the time at constant temperature. Diagrams of front views, derived from six of the eight diagrams of figures 1 to 5 , are shown in figures 13,14 , and 15 .

The relation between film thickness $(y)$, wavelength $(\lambda)$, index of refraction $(\mu)$, and the order $(b)$ of the interference color, is expressed by the equation

$$
y=\frac{(2 b-1) \lambda}{4 \mu}
$$

The observed color depends not only on interference between the light reflected from the bottom of the oxide film and that reflected from the top, but also upon the selective absorption of light by the metal and the oxide film. This dependence was studied for nickel and $451601-42-3$ 
copper, the metals that would be expected to show the most prominent influence of selective absorption. For this investigation, specimens of these two metals, some with and some without oxide films, were examined by means of a recording spectrophotometer. ${ }^{4}$

The variation of the reflectance of the specimen with the wavelength of the incident light was determined, and from these measurements the reflectance ratio (the ratio of the reflectance of the oxidized surface to the reflectance of the unoxidized surface) was computed. The use of the reflectance ratio, rather than simply the reflectance of the oxidized specimen, permits the selective absorption of light in the oxide film to be evaluated independently of the selective absorption of light by the metal itself. Figures 11 and 12 show the variation of the reflectance ratio with the wavelength. Since the film thickness corresponding to an interference color is, according to eq 2, a function of the wavelength of the extinguished light, the significant part of a curve in these figures is the wavelength of the minimum reflectance ratio. From the curves for nickel (fig. 11) the wavelength for the minimum reflectance ratio may be readily estimated for brown of the first and second orders and for first-order blue. No minimum is found in the curve of reflectance ratio for first-order straw color, but the curve evidently is approaching a minimum which would be at a wavelength somewhat below the short-wave limit of the spectrophotometer used. An estimated value of $3500 \mathrm{~A}$ has been taken for this minimum. Similarly for copper all curves in figure 12 yield definite minima except that for second-order straw color, which is evidently approaching a minimum at a wavelength not far below the short-wave limit of the spectrophotometer used. The reflectance ratios for copper differ from those for nickel by being lower in the long-wave end of the spectrum. This difference must be ascribed to difference in selective absorption of light by the two oxide films, and not to interference effects. No attempt has been made to take this difference into account in estimating the wavelength corresponding to the light extinguished by interference. These wavelengths have been taken from figures 11 and 12 for determining oxide-film thickness by eq 2 for nickel and copper. For other metals the wavelengths of the light extinguished by interference have been taken as 3500,4500 , and $6300 \mathrm{~A}$, corresponding to straw color, brown, and blue, respectively.

As indicated by eq 2 , the absolute thickness of the oxide film cannot be determined without knowledge of its index of refraction, for light of wavelength equal to that of the extinguished component. For some of the nonferrous metals studied, neither the indices of refraction nor their variation with wavelength are known. It was therefore found convenient not to use any recorded values of the refractive index to obtain film thickness by eq 2. Instead, as in the previous paper [10], a value of 1.0 was used for $\mu$. The thicknesses so obtained refer to the distance to which the two film faces would have to be separated by air in order to obtain the interference effects observed. These thicknesses have therefore been identified as "uncorrected airequivalent values."

\section{GENERAL DESCRIPTION OF THE DIAGRAMS}

Abscissas in these front views (figs. 13, 14, and 15) of three-dimensional diagrams, like abscissas in the plan views (figures 1 to 5), repre-

1 Acknowledgment is made to H. J. Keegan, of the Colorimetry and Spectrophotometry Section, for making the spectrophotometric measurements and for helpful suggestions in regard to assembling this information. 
sent the logarithms of the first powers of the oxidation times. The scale of abscissas, however, is more condensed in the front views than in the plan views. The variations of slope of the curves have been magnified by using as ordinates the fifth powers of the film thickness (tenth powers are used in the corresponding diagrams of the previous paper). The letters used to designate the interference colors at the right of each figure have the same significance as in figures 1 to 5 .

Each small open circle in figures 13,14 , and 15 corresponds to a point on each of the straight graphs of the plan view; each black circle corresponds to a point obtained by extrapolation of one of these straight graphs. Each curve is based not only on the corresponding small circles, but also on the interrelationship between all the curves of the diagram and on the interrelationship between the front view, plan view, and side elevation (figs. 16 and 17) of the three-dimensional diagram.

\section{FORM OF THE CURVE OF VARIATION OF FILM THICKNESS WITH TIME AT CONSTANT TEMPERATURE}

The curves in figures 13,14 , and 15, with the exception of those in the diagram for copper (fig. 15), are qualitatively similar to the corresponding curves for steels [10]. Each curve (with the exception of those for copper) increases in slope as it extends to the right, and all the curves evidently approach the same slope (indicated by the broken lines). ${ }^{5}$ The tangent of the angle of this slope is 2.5 , but would be 0.5 if the first powers of the film thickness were used as ordinates. A straight line having this slope, with logarithmic coordinates, represents a quadratic parabola. When this slope is reached, therefore, the film thickness is varying as the square root of the oxidation time [10]. The thickness at which the quadratic relationship is reached decreases with increase in the temperature, and also varies with the metal; it is less for tungsten, ${ }^{6}$ lead, and silicon than for nickel and zinc.

The slope of a curve (figs. 13, 14, and 15) at any point may be represented by the equation

$$
m=\frac{d \log y}{d \log t}=(t / y)(d y / d t) .
$$

In this equation, $y$ and $t$ have the same significance as in previous equations, and $m$ represents the tangent of the angle of slope, when the coordinates represent the first powers of the two variables. The value of $m$ for the asymptote approached by the curves is 0.5 .

The curves in the diagram for copper (fig. 15) extend not only through the range of interference colors, but also to a point representing a much thinner film. The wider range of film thickness represented in this diagram is made possible by including evidence based on results obtained by Lustman and Mehl [9],7 who used polarized light in an investigation of very thin films. Throughout the range of interference colors, the curves are less exactly established

\footnotetext{
3 The downward convexity of these curves, as shown in the previous paper [10], does not mean that the curves would have this form if plotted with Cartesian coordinates. If so plotted, as illustrated in figure 20, the slope decreases continuously with increase in the oxidation time.

6 The diagram for tungsten does not support Scheil's conclusion [i5] that the thickness of the oxide film on this metal increases linearly with the oxidation time.

7 Neither this diagram nor the diagrams for the other metals supports the conclusion by Lustman and $\mathrm{Mehl}[9]$ that the oxidation rate of metals at low tem peratures changes discontinuously with the temperature.
} 
than are the curves for the nonferrous metals previously considered. As shown in the plan view (fig. 4), the scatter of the experimental points is too great to permit exact location of the graphs from which the corresponding experimental points in figure 15 are derived. Nevertheless, the evidence based on this investigation and on the investigation by Lustman and Mehl is sufficient to establish the approximate form and position of these curves.

Throughout the range of interference colors on copper (fig. 15) the curvature is slight, and the approach to a quadratic relationship is much slower than in the diagrams for the other metals here considered. Even at a thickness corresponding to third-order blue, the slope of each curve is considerably less than that representing a quadratic parabola.

The reversal of curvature with extension of the curves into the field representing films too thin to exhibit interference colors is based on data presented by Lustman and Mehl [9]. Curves $L$ representing these data have been corrected to allow for the fact that the data recorded by Lustman and Mehl represent estimated values of both the actual film thickness and the index of refraction, whereas film thicknesses in figure 15 are "air-equivalent" values. Correction has also been made by subtracting 35 seconds from the oxidation times recorded by these investigators. As their experiments involved removal of hydrogen and admission of a rapid stream of air (not preheated), some deduction apparently should be made from the recorded oxidation times. Moreover, their diagrams and a statement in their paper indicate that practically no film was formed during an initial period of about 35 seconds. The deduction of 35 seconds from the oxidation times has made the slope of the lower parts of curves $L$ in figure 15 somewhat less steep than if the curves were uncorrected.

The curves based both on this investigation and on that of Lustman and Mehl, consequently, are less steep at the lower ends than curves based only on the latter investigation. For very thin films the curves (fig. 15) approach a tangent whose slope would be 1.0 if the first powers of the film thicknesses were used as ordinates; they thus indicate that thickness is proportional to oxidation time. The film thickness represented by the lower ends of the curves is only $10 \mathrm{~A}$, and hence the number of atomic layers in the film is of the order of 10 .

The diagram for copper (fig. 15) is the only diagram of this type, either in this paper or the preceding paper [10], in which there is experimental evidence of a reversal of curvature. In all the other diagrams, the curves at their lower ends turn rapidly to the left. If these curves could be extended further, however, they all probably would eventually show a reversal and an approach to a final steep slope. This surmise is illustrated by the assembled curves in figures 18 and 21 , which are discussed in section VII.

\section{VARIATION OF THE FILM THICKNESS WITH TEM- PERATURE, FOR CONSTANT OXIDATION TIME}

\section{GENERAL DESCRIPTION OF DIAGRAMS}

Two views of each three-dimensional diagram representing the oxidation of these nonferrous metals have already been considered. The third view, a side elevation, represents the variation of the film 
thickness with temperature, for constant oxidation time. Such views of six diagrams are shown in figures 16 and 17 . For correct representation of the side elevations, abscissas read from right to left. Abscissas represent the logarithms of the tenth powers of the absolute temperatures, and ordinates represent the logarithms of the fifth powers of the film thicknesses. The scale dimension, however, is twice as large for abscissas as for ordinates. For each diagram except that for copper (fig. 17), the powers of the variables are the same as for the corresponding coordinates in the plan view and front view.

The side elevation can be derived from either the plan view or the front view. The small circles in figures 16 and 17 are derived from corresponding points on graphs of the plan views. The black circles represent results of some extrapolation. Each curve is based not only on the positions of the corresponding symbols, but also on the probable interrelationship between all the curves of the diagram, and on the proper relationship between the side elevation and the corresponding plan and front views.

\section{FORM OF THE CURVES OF VARIATION OF FILM THICKNESS WITH TEMPERATURE, FOR CONSTANT OXIDATION TIME}

The curves in the side elevations (figs. 16 and 17) are qualitatively similar to the curves in the front views (figs. 13, 14, and 15). The slope increases with the temperature, and each curve apparently approaches a steeply sloping asymptote. The slope of a curve at any point is represented by the equation

$$
h=\frac{d \log y}{d \log T}=(T / y)(d y / d T) .
$$

In this equation, $T$ represents the absolute temperature, and $h$ represents the tangent of the angle of slope, if the coordinates represent the first powers of the two variables. In figures 16 and 17 , the relation between the powers of the two variables and the scale dimensions are such that $h$ is one-fourth the indicated slope.

With increase in the film thickness, the three-dimensional diagram approaches an inclined plane. The relation between the inclinations of this plane in the plan view, front view, and side elevation is represented by the following relation between the three indices of slope

$$
h=m n \text {. }
$$

An asymptotic value of $h$, therefore, can be obtained by the use of the asymptotic value of $n$ and the asymptotic value 0.5 for $m$. The asymptotic value of $h$ varies with the metal. For the metals represented in figures 16 and 17 and in table 1 , the values of $h$ range between about 11 and 22. For constant oxidation time, therefore, the film thickness varies as about the 11 th to the $22 \mathrm{~d}$ power of the absolute temperature.

With downward extension of the curves for nickel (fig. 16), they probably would cross the corresponding curves for lead. Similar evidence in figure 17, moreover, suggests that the curves for zinc would cross the corresponding curves for copper. In this respect, these pairs of diagrams are similar to the corresponding pairs of diagrams for carbon steels and high chromium steels shown in figures 27 and 28 of the previous paper [10]. Up to a certain film thickness, which varies 
with the metal, high-chromium steels evidently oxidize more readily than carbon steels, nickel oxidizes more readily than lead, and zinc oxidizes more readily than copper. Above these thicknesses, the relative resistance to oxidation of the metals of each of these pairs is reversed. Reasons for this behavior will be discussed later.

\section{FACTORS AFFECTING THE FORM AND POSITION OF THE THREE-DIMENSIONAL DIAGRAM REPRESENTING THE OXIDATION OF A METAL}

\section{INFLUENCE OF THE AFFINITY OF THE METAL FOR OXYGEN ON THE RATE OF DIFFUSION THROUGH THE OXIDE FILM}

The relative resistance of chromium steels and carbon steels to oxidation varies greatly with the film thickness. When the film is very thin, chromium steels oxidize more rapidly than carbon steels $[10,13$, 16]. With increase in the film thickness, however, the relative resistance of chromium steels increases, and eventually becomes greater than that of carbon steels. The film thickness at which this inversion of relationship occurs decreases with increase in the chromium content, at least up to about 13 percent. As shown by Portevin, Prétet, and Jolivet [13], the tendency of the metal to cross the metal-film interface is greater for chromium than for iron, but the chromium ions diffuse outward more slowly than the iron ions. Oxide of chromium thus tends to become concentrated in a layer at the inner surface of the oxide film. Through this layer, the outward diffusion of ions of iron is less rapid than through oxide of iron. When enough chromium has been oxidized to build up a certain thickness of chromium oxide, therefore, a chromium steel oxidizes less rapidly than a carbon steel.

A similar effect $[13,16]$ is produced by other alloying elements whose affinity for oxygen is greater than that of iron (as shown by a greater heat of formation of the oxide). Among such elements are aluminum and silicon. An investigation by Scheil and Kiwit [16] led them to the conclusion that the oxidation-resistance of steel is improved by alloying with elements less noble, such as aluminum, chromium, silicon, vanadium, molybdenum, and beryllium. The oxides of these elements were found to be concentrated in the inner layer of the oxide film. For highest resistance to oxidation, they suggest also that the oxide of the alloying element should have a high melting point.

The effect of alloying elements on the oxidation of copper was studied by Fröhlich [8]. He investigated the effect of additions of aluminum, iron, lithium, magnesium, manganese, nickel, arsenic, boron, beryllium, chromium, calcium, cerium, cobalt, phosphorus, antimony, silicon, titanium, zinc, tin, and silver. Of all these elements, only silver is more noble than copper. In the oxidation of all these alloys except the copper-silver alloy, the oxide of the alloying element was found to be concentrated in the inner layer of the oxide film.

The evidence indicates that the ions of a less noble metal alloyed with either iron or copper diffuse outward less rapidly than the ions of the predominant metal, and thus form an inner layer of oxide with relatively high resistance to diffusion. It would be expected, therefore, that an unalloyed metal with high affinity for oxygen would tend to form quickly a thin protective film of oxide, and thus would acquire 
high resistance to further oxidation. It might even be expected that the greater the affinity of the metal for oxygen, the more rapidly would the metal oxidize at first and the more slowly would it oxidize after this initial period. This would imply that the resistance of the film to outward diffusion of metal ions and electrons tends to increase with increase in the affinity of the metal for oxygen. It would imply further that, for a film of sufficient thickness, the resistances of metals to oxidation would be in the order of their chemical affinities. If this surmise were correct, the heights of the graphs representing first order (or a color of a higher order) for various metals would be in the order of their chemical affinities. The correctness of this implication will be tested by a comparison of the assembled graphs in figure 10 with the data in table 2.

The assembling of the graphs in figure 10 is not only for a comparison of the resistances of these metals to oxidation, but also for a comparison of these resistances with various physical properties of the oxides. The oxides are listed in table 2 in the order of decreasing heats of formation per gram atom of oxygen. For evaluation of the relative resistances to oxidation, the positions of the graphs in figure 10 have been corrected to allow for the differences in the indices of refraction of the oxides and in the volume of oxide per gram atom of oxygen (columns 11 and 12 of table 2). As shown in eq 2, the film thickness for a given interference color is inversely proportional to the index of refraction of the oxide. The higher the index of refraction and the greater the volume of oxide per gram atom of oxygen, therefore, the sooner will a given interference color appear. The factor used in correcting the position of each graph in figure 10, consequently, is the product of the factors listed in columns 11 and 12 of table 2; these products are listed in column 13. The amounts of the corrections may be seen by comparing the positions of corresponding graphs in figures 8 and 10. The greatest corrections are in the positions of the graphs for lead and copper.

The relative heights of the graphs at two positions in figure 10 are listed in columns 7 and 8 of table 2 , and have been indicated by numbers adjacent to some of the graphs. Comparison of columns 2, 7 , and 8 of table 2 shows some evidence of a correlation between the order of decreasing heats of formation of the oxides and the order of decreasing heights of the graphs. The graphs for aluminum, silicon, and chromum, whose oxides have high heats of formation, are near the top of the diagram; the graphs for lead and copper, whose oxides have relatively low heats of formation, are at the bottom of the diagram. Moreover, it is easy to account for the relatively high position of the graphs for rhodium and ruthenium, whose oxides have the lowest heats of formation. Parallelism between the order of decreasing heats of formation and the order of decreasing heights of the corresponding graphs could not continue below a certain value of the heat of formation. When the heat of formation is less than this value, the chemical affinity is so slight that the rate of oxidation is controlled throughout by the slow rate of transfer across the interface rather than by the resistance of the film to diffusion. It is not surprising, therefore, to find that the graphs for rhodium and ruthenium are much higher than the graph for copper.

The other graphs in figure: 10 show no clear correlation between the heats of formation and the rate of oxidation. The graphs for man- 
ganese, tantalum, vanadium, and zirconium, whose oxides have high heats of formation, are near the middle of the diagram. The graph for nickel, moreover, is much too high, and the graphs for iron and manganese are much too low, to be correlated with the order of the heats of formation. The graph for nickel is much higher than that for cobalt, although the oxides of these metals have about the same heat of formation.

The affinity of the metal for oxygen, however, is not measured exactly by the heat of formation, but is measured by the free energy at the temperature of the reaction. The free energies of oxidation at $25^{\circ}$ and $427^{\circ} \mathrm{C}$, for some of the metals, are listed in columns 4 and 5 of table $2^{8}$. Because the entropy values are not known for some of the oxides, the free energies for these metals could not be calculated. As the free-energy values in both columns are in the same order as the heats of formation, they give no better correlation with the relative positions of the graphs in figure 10. In column 6 of table 2 are listed values of free energy for the different indicated temperatures, which are approximately the temperatures represented by the middles of the corresponding graphs in figure 10. These values also are in the order of decreasing heats of formation of the oxides.

The lack of parallelism between the chemical affinities and the relative positions of the graphs cannot be attributed to differences in the melting points of either the metals or the oxides, or to differences in the boiling points of the metals. This is shown by a comparison of the data in columns $7,8,14,15$, and 16 of table 2 .

No consistent relation, therefore, exists between the order of decreasing chemical affinity and the order of positions of the graphs in figure 10. This evidently means that the order of decreasing chemical affinity is not the order of decreasing resistance to diffusion through the oxide film. The resistance to diffusion through the film in most metals evidently is affected greatly by factors other than the chemical affinity of the metal for oxygen. As shown in section II, the mode of transfer of the ions and electrons through the oxide film varies greatly with the metal. This difference in the mode of transfer probably is associated with great differences in the resistance to diffusion.

\section{INFLUENCE OF THE AFFINITY OF THE METAL FOR OXYGEN ON THE INITIAL RATE OF OXIDATION}

If sufficient evidence were available, a correlation might be found between the affinity of a metal for oxygen and the initial rate of oxidation. The fact that the initial rate of oxidation is greater for an iron-chromium, iron-silicon, or iron-aluminum alloy than for iron suggests that the initial rate depends upon the affinity of the metal for oxygen. A similar suggestion is given by the evidence in figure 16 that, the curves for nickel, if extended far enough downward, would cross the corresponding curves for lead, and by the evidence in figure 17 that the curves for zinc would cross the curves for copper. Additional evidence is revealed by a comparison of the assembled curves in figures 18 and 19.

The experimentally established portion of each curve in figures 18 and 19 is drawn as a continuous line. The curve for copper, because of

${ }^{8}$ Acknowler gment is made to F. D. Rossini, of this Bureau, for helpful suggestions in regard to assembling this information. 
its experimental basis, is drawn as a continuous line throughout its entire extent. Each other curve is extended downward, as a broken line, far below the field representing the range of experimentally determined points. The lower limit of the diagram represents a film thickness of not much more than $100 \mathrm{~A}$, or about the same number of atomic layers. This downward extension of the curves is intended to indicate only qualitatively the forms and the probable interrelationship of the curves.

In a diagram of the type shown in figure 18, the assembled curves should, if possible, represent results obtained at the same temperature. Such an ideal representation, however, was not possible; five of the curves represent results obtained at two slightly different temperatures, and the curves for copper and iron represent results obtained at a much lower temperature. The diagram, however, makes it possible to deduce the approximate relative positions of the curves in an ideal diagram of this type."

If curves for copper and iron were obtained at a temperature of $600^{\circ} \mathrm{C}$, they evidently would be far to the left of the curves for the same metals at $200^{\circ} \mathrm{C}$, and probably would be beyond the boundary of the diagram. They, therefore, would not cross the curve for ruthenium, but probably would cross the curves for tungsten and nickel. The previously discussed evidence that the initial rate of oxidation is higher for a chromium steel than for a carbon steel $[10,13,16]$ indicates that the curve for 24.4-percent chromium steel in figure 18 would eventually cross a curve obtained with electrolytic iron at the same temperature, $600^{\circ} \mathrm{C}$. This evidence, together with the course of the established portion of the curve, indicates that the leftward extension of the curve for 24.4-percent chromium steel in figure 18 is approximately correct. The curve thus crosses the curves for tungsten and nickel. A curve for chromium (not shown) probably would take about the same course. Similar evidence $[10,13,16]$ suggests that the curve for silicon should take the indicated approximate course and should eventually cross a curve obtained with iron at the same temperature, $600^{\circ} \mathrm{C}$.

In figure 19, each curve represents the variation of film thickness with temperature, for a constant oxidation time of 1,000 minutes. This diagram, therefore, represents directly the relative resistance of the indicated metals to oxidation. The courses of the established parts of the curves for nickel, tungsten, zinc, iron, and 24.4-percent chromium steel, together with other evidence previously mentioned, show that the extrapolated portion of the curve for 24.4-percent chromium steel takes the indicated approximate course, thus crossing the curves for the other four metals. There is little doubt, moreover, that the curve for the 24.4-percent chromium steel should cross, as indicated, the curves for lead and copper. A similar course probably would be taken by a curve for chromium. The curve for silicon, in view of the previously mentioned evidence that the initial rate of oxidation is higher for silicon steels than for iron, should extend rapidly to the right, as in figure 19, thus crossing the curves for ruthenium, nickel, tungsten, zinc, iron, lead, copper, and possibly chromium (not shown).

The established portion of the curve for ruthenium (fig. 19) suggests that this curve, with downward extension, remains to the left of the 
other curves. A similar course would doubtless be taken by a curve for rhodium (not shown).

With sufficient downward extension, all the curves in figures 18 and 19 would probably reverse their curvature and approach a steep tangent at a film thickness of one atomic layer (about $1 \mathrm{~A}$ ). In a diagram of the type shown in figure 18, the slope of the tangent probably would be 1.0, if ordinates represented the first powers of the film thickness. In the figure, this slope is indicated by the broken lines extending from the lower boundary.

At a film thickness corresponding to first-order blue, the curves in figure 19 are necessarily in the same relative positions as in figure 10. At a film thickness less than about $500 \mathrm{~A}$, however, the curves in figure 19 are in very different relative positions. Silicon and 24.4percent chromium steel, which have high resistance to oxidation at first-order blue, have low resistance at a film thickness of less than about $500 \mathrm{~A}$. Copper and lead, which have relatively low resistance to oxidation at first-order blue, have high initial resistance. Ruthenium, the metal with the lowest affinity for oxygen, has the highest initial resistance to oxidation, and the resistance remains high throughout the range of interference colors. As stated in discussion of figure 10 , such behavior would be expected when the affinity of a metal for oxygen is very low.

The evidence in figures 18 and 19 indicates that the initial rate of oxidation tends to be high or low according as the metal has high or low affinity for oxygen. Additional evidence, however, is needed to show whether the order of increasing affinity is the order of increasing initial rate of oxidation. The horizontal distance between the tangent to a curve at its origin, at a thickness of one atomic layer, and the asymptote finally approached by the curve evidently tends to increase with increase in the affinity of the metal for oxygen. (Compare the curves for silicon and copper in figs. 18 and 19.)

\section{REASONS FOR THE COMPLEX VARIATION OF THE RATE OF OXIDATION WITH THE FILM THICKNESS}

The complexity of the variation of the rate of oxidation with film thickness is shown by the reversals of the curves drawn with logarithmic coordinates in figures 18 and 19 , and is strikingly revealed in diagram $A$ of figure 21 , in which the ordinates represent first powers of the film thickness. If all the curves in figure $21(A)$ were extended downward far enough, they eventually would reverse their curvature. It is assumed, for reasons to be given, that they would approach a $45^{\circ}$ tangent, as do the curves for copper and ruthenium. Such an initial slope of the curves implies an initial linear relation between film thickness and oxidation time. With upward extension, the slope of each curve decreases rapidly and traverses a minimum. The curves then approach asymptotes whose slope $(0.5)$ is that of a quadratic parabola.

The fact that there is a minimum slope in the curves drawn with logarithmic coordinates does not mean that the rate of oxidation traverses a minimum. This is illustrated by the curves in figure 20 representing the oxidation of zinc at various temperatures. The curves in this figure, drawn with Cartesian coordinates, decrease continuously in slope. Comparison of these curves with the parabolas 
in the figure, however, reveals the same complexity of form that is shown in figures 18 and 21 . The possible reasons for this complexity will now be considered.

The complex variation of the rate of oxidation with film thickness evidently signifies a similarly complex variation of the rate of movement of ions and electrons through the oxide film. If the concentration of the metal ions in the film falls linearly from the value at the metal-film interface to zero at the film-air interface, the steepness of the concentration gradient would vary inversely as the film thickness. The rate of oxidation at any instant, therefore, would be

$$
d y / d t=D / y
$$

in which $D$ is the specific diffusivity, generally assumed to be a constant. This constant depends on the oxide, on the mobility of the ions, and on the temperature. By integration, this leads to the equation of the parabolic law,

$$
y^{2}=2 D t+c,
$$

in which $c$ is a constant of integration.

The parabolic law operates only when the film has become so thick that the rate of oxidation is controlled by the rate of diffusion through the film. Before this condition is reached, the rate of oxidation would depend somewhat on the rate of transfer of ions across the metal-film interface. The rate of transfer across this interface probably is the controlling factor immediately after the formation of a single atomic layer of oxide. Both this factor and the influence of the rate of diffusion are represented in an equation developed by Evans [5]. This equation, developed before Wagner and coworkers [1 to 4, 18, $19,20]$ showed that the dry oxidation of metals is an electrochemical process, is the same in form as an equation developed by Fischbeck $[6,7]$ as part of a general study of the rates of reaction of solids with gases.

The equation, with the symbols altered, is

$$
d y / d t=E /\left(W_{1}+W_{D}\right) \text {. }
$$

In this equation, $E$ is proportional to the potential of the reaction (as measured by the free energy). $\quad W_{1}$ represents the resistance to transfer of metal ions and electrons across the metal-film interface, and $W_{D}$ is the resistance to diffusion through the film. ${ }^{9}$ The resistance $W_{D}$ depends both on the film thickness and on the mean resistivity, $R$, of the film. Consequently,

$$
W_{D}=R y,
$$

in which $R$ is the reciprocal of the specific diffusivity, $D$, assumed to be constant in the derivation of the parabolic law. By substitution, eq 8 becomes

$$
d y / d t=E /\left(W_{1}+R y\right) \text {. }
$$

\footnotetext{
- It appears unnecessary here to divide $W_{1}$ into two components representing resistances at both interfaces.
} 
When the film is so thick that $W_{1}$ is negligible in comparison with $W_{D}$, the equation becomes

$$
d y / d t=E / R y,
$$

the equation of a quadratic parabola. When the film is so thin that $W_{D}$ is negligible in comparison with $W_{1}$, the equation becomes

$$
d y / d t=E / W_{1},
$$

the equation of a straight line. Plotted with logarithmic coordinates, it would have a slope 1.0. This equation, therefore, is the basis of the assumption in figures 18 and 21 that the tangent to a curve at a film thickness of one atomic layer has a slope 1.0 or $45^{\circ}$.

The actual curves in a diagram of the type shown in figures 18 and $21(A)$, however, are very different from a curve derived from eq 10. By integration eq 10 becomes

$$
t=\frac{1}{E}\left(W_{1} y+\frac{R y^{2}}{2}\right)
$$

This equation evidently represents the superposition of the abscissas of a straight line and a quadratic parabola. In diagram $B$ of figure 21, lines 1 and 2 represent a straight line and a quadratic parabola, respectively. ${ }^{10}$ Superposition of corresponding abscissas (not their logarithms) of curves 1 and 2 results in curve 3. This curve starts tangent to a $45^{\circ}$ line and approaches asymptotically a line whose slope is 0.5 . As the curve has no reversal, however, it is very different from the curves shown in diagram $A$. All the curves of diagram $A$, if extended far enough downward, probably would be qualitatively similar to the curves for copper and ruthenium. At the lower ends they probably would have a $45^{\circ}$ tangent; at the upper ends, they would approach a 0.5 slope. In this respect, they resemble curve 3 of diagram $B$. Between these two slopes, however, each of the curves in diagram $A$ has a reversal. (In a curve for a metal with high affinity for oxygen, such as silicon, the abscissa range between the initial $45^{\circ}$ slope and the asymptote is very great.) To account for this great difference in form between curve 3 of diagram $B$ and the curves of diagram $A$, a modification must be made in the assumptions that are the basis of curve 3 and eq 13 .

Equation 13 is based on the assumption that the resistance to transfer of ions and electrons through the oxide film can be expressed as the product of the film thickness and a resistivity, $R$, independent of the film thickness. The complexity of the curves in figure $21(A)$, however, makes it necessary to abandon the assumption of a constant resistivity. Whatever may be the interpretation in terms of fundamental factors, the variation of the rate of oxidation with the film thickness may be expressed in terms of a variation of the resistivity with the film thickness. On this assumption, the term $R y$ in eq 10 would become

\section{$\int R d y$.}

\footnotetext{
10 The relative positions of these two lines depend on the chosen values of the constants, $E, W_{1}$, and $R$.
} 
A curve representing qualitatively the probable relation between $R$ and $y$ is shown in figure $21(C)$. The area underneath the curve, between abscissas zero and $y$, is

$\int R d y$.

The mean value, $M$, of $R$ between these limits is

\section{$\left(\int R d y\right) / y$.}

The variation of $M$ with $y$ (fig. $21, C$ ) evidently is qualitatively similar to the variation of $R$. From eq 10, therefore, may be derived

$$
d y / d t=E /\left(W_{1}+M y\right) .
$$

In order that eq 14 may give a curve of the form of those shown in figure $21(A), R$ (or $M$ ) must increase with $y$ as represented qualitatively by the curve in figure $21(C)$; the greater part of the increase of $R$ must be within a relatively narrow range of $y$. The reversal of curvature of $R$ is at about the same film thickness as the reversal of a curve of the type shown in figure $21(A)$. Near the origin of the curve in figure $21(C)$, the value of $R$ is only about 2 percent of the asymptotic value approached after the reversal of curvature. A similar curve, except that the initial value of $R$ is only 1 percent of the asymptotic value, has been used in the construction of curve 6 of figure $21(B)$. Curve 6 is obtained by superposition of the corresponding abscissas of curves 4 and 5 .

This synthetic curve is qualitatively similar to the curves in figures 18 and $21(A)$. It resembles most closely the curves for ruthenium and copper in figure $21(A)$. To make such a synthetic curve resemble a curve for a metal with high affinity for oxygen (such as silicon), however, the ratio of the initial value of $R$ to the asymptotic value must be much less than 1 percent. For some metals, the ratio evidently may be of the order of $10^{-6}$ or less.

The resistivity of the oxide film, therefore, is not constant, but increases first at an increasing, then at a decreasing rate. After a relatively abrupt increase within a narrow range of film thickness, the resistivity approaches a constant value. Beyond this range of rapid increase of resistance, consequently, the growth of the film is approximately in accordance with the parabolic law.

In expressing the complex variation of the rate of oxidation in terms of a variation of the resistivity, there is no intention to attribute the variation of the resistivity to any particular variable, such as electrical resistance. The evidence merely indicates that a film behaves as if its resistivity to the transfer of ions and electrons varies in the manner described. The authors have found no entirely satisfactory theory to account for this variation. According to Mott $[11,12]$, the rate of oxidation is determined by a quantum mechanical "tunneling" of electrons up to a thickness of about $50 \mathrm{~A}$; at this thickness, the tunneling is stopped by the electrostatic attraction between the metal and electrons. His theory calls for an approach to an exponential relationship at a film thickness of about $50 \mathrm{~A}$ at room temperature. According to Lustman and Mehl [9], however, 
this theory would not satisfactorily account for the large effect of temperature on the rate of oxidation. This objection to Mott's theory is illustrated by the curves for zinc in figure 20 . At $200^{\circ} \mathrm{C}$, the curve becomes nearly horizontal at an air-equivalent thickness of more than 2,000 A (about 1,000 A actual thickness if corrected for index of refraction), whereas Mott's curve for aluminum at room temperature becomes nearly horizontal at only $50 \mathrm{~A}$.

The curves in figure $21(A)$ apparently give little basis for the assumption of an exponential relationship. Moreover, they give no support to the conclusion of Lustman and Mehl [9] that this region can be represented by two successive exponential curves.

It is possible that the rapid increase in resistivity within a narrow range of film thickness is due to a change of lattice structure.

The authors hope that the evidence presented in this paper will stimulate further investigation of the fundamental factors responsible for the complex variation of the rate of oxidation with the film thickness.

\section{SUMMARY}

An investigation has been made of the rate of oxidation of 18 nonferrous metals by means of the interference colors of oxide films. With eight of these metals complete diagrams were obtained; with seven metals the approximate forms and positions of the graphs were obtained for interference colors of the first order; with three metals, only the approximate positions of the graphs were obtained. A comparison is made between the results obtained with these metals and with typical steels.

The diagrams obtained with these nonferrous metals are similar to those obtained with steels [10]. For a constant film thickness, the relation between temperature and oxidation time is linear when plotted with logarithmic coordinates. The variation of the film thickness either with time at constant temperature or with temperature for constant oxidation time, when plotted with logarithmic coordinates, is represented by a reversed curve. When plotted with Cartesian coordinates, the variation of film thickness with time at constant temperature is represented by a curve without reversal; this is a complex curve becoming approximately parabolic at the upper end.

An attempt is made to correlate the forms and positions of the curves with the affinities of the metals for oxygen, with the resistances at the metal-oxide interface, and with the resistivity of the oxide film. The variation of the rate of oxidation with the film thickness is such that it may be expressed in terms of an assumed variation of the resistivity with the film thickness. This means merely that the film behaves as if its resistivity (not necessarily its electrical resistance) varies in the manner described.

\section{REFERENCES}

[1] H. H. Baumback and C. Wagner, Die elektrische Leitfähigkeit von Zinkoxyde und Cadmiumoxyd, Z. physik. Chem. [B] 22, 199-211 (1933).

[2] H. H. Baumback, H. Dünwald, and C. Wagner, Leitfähigkeitsmessungen an Kupferoxyde, Z. physik. Chem. [B], 22, 226-230 (1933).

[3] H. Dünwald and C. Wagner, Die Natur der elektrischen Leitfähigkeit von Kupferoxydul, Z. physik. Chem. [B] 17, 467-470 (1932). 
[4] H. Dünwald and C. Wagner, Untersuchungen über Fehlordnungserscheinungen in Kupferoxydul und deren Einfluss auf die eleltrischen Eigenschaften, Z. physik. Chem. [B] 22, 212-225 (1933).

[5] U. R. Evans, The relation between tarnishing and corrosion, Trans. Am. Electrochem. Soc. 46, 247-272 (1924).

[6] K. Fischbeck, Über das Reaktionsvermogen der festen Stoffe, Z. Elektrochemie 39, 316-330 (1933).

[7] K. Fischbeck, L. Neundeubel, and F. Salzer-Tubingen, Über das Reaktionsvermögen von Kristallarten, Z. Electrochemie 40, 517-522 (1934).

[8] K. W. Fröhlich, Die Zunderung von reinen und von legierten Kupfer, Z. Metallkunde 28, 368-375 (1936).

[9] B. Lustman and R. F. Mehl, Low temperature oxidation of single crystals of copper, Metals Tech. 8, T. P. 1317 (1941).

[10] D. J. McAdam, Jr., and G. W. Geil, Rate of oxidation of steels as determined from interference colors of oxide films, J. Research NBS 23, 63-124 (1939) RP1221.

[11] N. F. Mott, A theory of the formation of protective oxide films on metals, Trans. Faraday Soc. 35, 1175-1177 (1939).

[12] N. F. Mott, The theory of the formation of protective oxide films on metals, Trans. Faraday Soc. 36, 472-483 (1940).

[13] A. M. Portevin, E. Prétet, and H. Jolivet, Contribution to the study of the chemical resistance of various special steels, J. Iron Steel Inst. (London) 130, 219-277 (1934).

[14] L. E. Price, Recent German advances in the mechanism of oxidation and tarnishing of metals, Chemistry \& Industry (J. Soc. Chem. Ind.) 15, 769-773 (1937).

[15] E. Scheil, Über das Zundern von Metallen und Legierungen, Z. Metallkunde 29, 209-214 (1937).

[16] E. Scheil and K. Kiwit, Einfluss von Legierungs Zusätzen auf das Zundern des Eisens, Arch. Eisenhüttenw. 9, 405-416 (1936).

[17] W. H. J. Vernon, E. I. Akeroyd, and E. G. Stroud, The direct oxidation of zinc, J. Inst. Metals 6, 253-281 (1939).

[18] C. Wagner, Theorie der geordneten Mischphasen, III, Z. physik. Chem. [B], 22, 181-194 (1933).

[19] C. Wagner, Theorie der Thermoketten von Halbleiterkombinationen, Z. physik. Chem. [B], 22, 195-198 (1933).

[20] C. Wagner and W. Schottky, Theorie der geordneten Mischphasen, Z. physik. Chem. [B], 11, 163-210 (1930).

TABLE 1.-Values for constants $n$ and $h$, representing, respectively, the variation of oxidation time with temperature for constant film thickness, and the variation of film thickness with temperature for constant oxidation time

\begin{tabular}{|c|c|c|c|c|c|c|c|c|c|c|}
\hline \multirow{3}{*}{ Material } & \multicolumn{8}{|c|}{$n$} & \multicolumn{2}{|c|}{$h$} \\
\hline & \multicolumn{3}{|c|}{ First-order- } & \multicolumn{3}{|c|}{ Second-order- } & \multirow{2}{*}{$\begin{array}{l}\text { Third- } \\
\text { order } \\
\text { blue }\end{array}$} & \multirow{2}{*}{$\begin{array}{c}\text { Fourth- } \\
\text { order } \\
\text { blue }\end{array}$} & \multirow{2}{*}{$\begin{array}{c}\text { Values } \\
\text { from } \\
\text { figures } \\
15 \text { and } \\
16\end{array}$} & \multirow{2}{*}{$\begin{array}{c}h=m n \\
(m=0.5)\end{array}$} \\
\hline & Straw & Brown & Blue & Straw & Brown & Blue & & & & \\
\hline $\begin{array}{l}\text { Nickel } \\
\text { Tungsten.- } \\
\text { Zinc } \\
\text { Lead. }\end{array}$ & $\begin{array}{l}25 \\
25 \\
23 \\
29\end{array}$ & $\begin{array}{l}35 \\
27 \\
29 \\
29\end{array}$ & $\begin{array}{l}36 \\
28 \\
33 \\
29\end{array}$ & & $\begin{array}{l}36 \\
29 \\
40 \\
--\end{array}$ & $\begin{array}{l}36 \\
29 \\
43 \\
29\end{array}$ & \begin{tabular}{r}
36 \\
30 \\
\hdashline-- \\
--
\end{tabular} & 31 & $\begin{array}{l}18 \\
15 \\
20 \\
18\end{array}$ & $\begin{array}{l}18 \\
15 \\
21.5 \\
14.5\end{array}$ \\
\hline $\begin{array}{l}\text { Silicon } \\
\text { Copper } \\
\text { Ruthenium } \\
\text { Vanadium }\end{array}$ & 24 & $\begin{array}{l}23 \\
26 \\
26 \\
31\end{array}$ & $\begin{array}{l}23 \\
26 \\
27 \\
33\end{array}$ & (n) & $\begin{array}{r}23 \\
26 \\
-34\end{array}$ & \begin{tabular}{c}
23 \\
26 \\
\hdashline--
\end{tabular} & $\begin{array}{l}23 \\
26 \\
-35\end{array}$ & 23 & \begin{tabular}{c}
11 \\
16 \\
\hdashline- \\
$-\cdots$
\end{tabular} & $\begin{array}{l}11.5 \\
13 \\
13.5 \\
17.5\end{array}$ \\
\hline $\begin{array}{l}\text { Electrolytic iron }{ }^{\mathrm{a}} \\
13.6 \% \mathrm{Cr} \text { steela } \\
24.4 \% \text { Cr steela }\end{array}$ & $\begin{array}{l}30 \\
32 \\
23\end{array}$ & $\begin{array}{l}30 \\
32 \\
33\end{array}$ & $\begin{array}{l}31 \\
32 \\
34\end{array}$ & $\begin{array}{l}34 \\
33 \\
35\end{array}$ & $\begin{array}{l}36 \\
33 \\
36\end{array}$ & $\begin{array}{l}38 \\
33 \\
36\end{array}$ & $\begin{array}{c}40 \\
-36\end{array}$ & $-\cdots$ & $\begin{array}{l}18 \\
18 \\
22\end{array}$ & $\begin{array}{l}20 \\
16.5 \\
19\end{array}$ \\
\hline
\end{tabular}

- Table.2. and figures 27 and 28 of previous paper [10]. 
TABLE 2.-Thermochemical and physical properties of metallic oxides

\begin{tabular}{|c|c|c|c|c|c|c|c|c|c|c|c|c|c|c|c|}
\hline \multirow{2}{*}{ Material } & \multirow{2}{*}{$\begin{array}{l}\text { Heat of } \\
\text { forma- } \\
\text { tion per } \\
\text { gram } \\
\text { atom of } \\
\text { oxygen } \\
\text { at } 18^{\circ} \mathrm{C}\end{array}$} & \multirow{2}{*}{$\begin{array}{l}\text { Entropy } \\
\text { per gram } \\
\text { atom of } \\
\text { oyxgen } \\
\text { at } 25^{\circ} \mathrm{C}\end{array}$} & \multicolumn{3}{|c|}{$\begin{array}{l}\text { Free energy of formation per } \\
\text { gram atom of oxygen }\end{array}$} & \multicolumn{2}{|c|}{$\begin{array}{l}\text { Order a of graphs in } \\
\text { figure } 10\end{array}$} & \multirow{2}{*}{$\begin{array}{l}\text { Index } \\
\text { of } \\
\text { refrac- } \\
\text { tion, } \mu\end{array}$} & \multirow{2}{*}{$\begin{array}{c}\text { Volume } \\
\text { per gram } \\
\text { atom of } \\
\text { oxygen, } \\
V\end{array}$} & \multicolumn{3}{|c|}{$\begin{array}{l}\text { Correction factors for posi- } \\
\text { tion of graphs in figure } 10\end{array}$} & \multicolumn{2}{|c|}{$\begin{array}{l}\text { Melting point } \\
\text { of- }\end{array}$} & \multirow{2}{*}{$\begin{array}{l}\text { Boiling } \\
\text { point } \\
\text { of } \\
\text { metal }\end{array}$} \\
\hline & & & At $25^{\circ} \mathrm{C}$ & At $427^{\circ} \mathrm{C}$ & $\begin{array}{c}\text { At in- } \\
\text { dicated } \\
\text { tempera- } \\
\text { tures }\end{array}$ & $\begin{array}{l}\text { At } 100 \\
\text { minutes }\end{array}$ & $\begin{array}{c}\text { At } 10^{5} \\
\text { minutes }\end{array}$ & & & $\begin{array}{c}\text { Factor }{ }^{b} \\
\text { for } \mu\end{array}$ & $\begin{array}{l}\text { Factor }{ }^{\circ} \\
\text { for } V\end{array}$ & $\begin{array}{c}\text { Product } \\
\text { of factors } \\
\text { for } \mu \\
\text { and } V\end{array}$ & Oxide & Metal & \\
\hline \multirow[t]{2}{*}{1} & 2 & 3 & 4 & 5 & 6 & 7 & 8 & 9 & 10 & 11 & 12 & 13 & 14 & 15 & 16 \\
\hline & $\begin{array}{r}k g-c a l \\
129.0 \\
126.7 \\
110.0 \\
101.7 \\
99.8\end{array}$ & \begin{tabular}{|c|}
$c a l$ \\
4.2 \\
7.8 \\
5.0 \\
6.8
\end{tabular} & $\begin{array}{c}k g-c a l \\
-125.5 \\
-104 \\
-95.2 \\
-\end{array}$ & $\begin{array}{r}k g-c a l \\
-86 \\
\end{array}$ & $\begin{array}{c}k g-c a l \\
-82\left(625^{\circ}\right) \\
\end{array}$ & $\begin{array}{r}14 \\
5 \\
11 \\
1 \\
7\end{array}$ & $\begin{array}{r}15 \\
5 \\
9 \\
1 \\
7\end{array}$ & $\begin{array}{r}2.2 \\
1.8 \\
\hdashline 1.5\end{array}$ & \begin{tabular}{r|}
$c m^{3}$ \\
10.8 \\
8.5 \\
10.3 \\
11.3 \\
10.1
\end{tabular} & $\begin{array}{r}1.00 \\
0.82 \\
.68\end{array}$ & $\begin{array}{r}1.03 \\
0.81 \\
.98 \\
1.08 \\
0.96\end{array}$ & $\begin{array}{l}1.03 \\
0.66 \\
.98 \\
.73 \\
.96\end{array}$ & $\begin{array}{l}{ }^{\circ} C \\
2,700 \\
2,050 \\
1,970 \\
1,470\end{array}$ & $\begin{array}{c}{ }^{\circ} C \\
1,900 \\
658.7 \\
1,720 \\
1,420 \\
2,850\end{array}$ & $\begin{array}{r}{ }^{\circ} C \\
>2,900 \\
1,800 \\
3,000 \\
2,600 \\
>4,100\end{array}$ \\
\hline $\begin{array}{l}\mathrm{MnO} \\
\mathrm{Cr}_{2} \mathrm{O}_{3} \\
\mathrm{Cb}_{2} \mathrm{O}_{3} \\
\mathrm{ZnO} \\
\mathrm{Fe}_{2} \mathrm{O}_{3}\end{array}$ & $\begin{array}{l}96.5 \\
91.0 \\
88.4 \\
83.5 \\
66.2\end{array}$ & $\begin{array}{r}14.4 \\
6.5 \\
10.4 \\
7.2\end{array}$ & \begin{tabular}{l}
-92.3 \\
-84.5 \\
\hdashline-76.3 \\
-60.0
\end{tabular} & $\begin{array}{l}-78 \\
-67 \\
-53\end{array}$ & $\begin{array}{l}-76\left(575^{\circ}\right) \\
-69\left(325^{\circ}\right) \\
-56\left(225^{\circ}\right)\end{array}$ & $\begin{array}{r}16 \\
2 \\
13 \\
9 \\
17\end{array}$ & $\begin{array}{r}17 \\
2 \\
14 \\
8 \\
16\end{array}$ & $\begin{array}{r}2.2 \\
2.5 \\
2.0 \\
3.2\end{array}$ & $\begin{array}{r}13.0 \\
9.7 \\
11.9 \\
14.5 \\
10.1\end{array}$ & \begin{tabular}{r}
1.00 \\
1.14 \\
\hdashline 0.91 \\
1.45
\end{tabular} & $\begin{array}{l}1.24 \\
0.92 \\
1.13 \\
1.38 \\
0.96\end{array}$ & $\begin{array}{l}1.24 \\
1.05 \\
1.13 \\
1.26 \\
1.39\end{array}$ & $\begin{array}{r}1,650 \\
1,990 \\
1,520 \\
>1,800 \\
1,565\end{array}$ & $\begin{array}{l}1,260 \\
1,615 \\
1,950 \\
419.5 \\
1,535\end{array}$ & $\begin{array}{r}1,900 \\
2,200 \\
2,900 \\
907 \\
\end{array}$ \\
\hline $\begin{array}{l}\mathrm{WO}_{3} \\
\mathrm{CdO} \\
\mathrm{MoO}_{2} \\
\mathrm{NiO} \\
\mathrm{CoO}\end{array}$ & $\begin{array}{l}65.2 \\
65.2 \\
65.0 \\
58.4 \\
57.5\end{array}$ & $\begin{array}{r}6.1 \\
13.1 \\
9.0 \\
14.5\end{array}$ & $\begin{array}{l}-58.9 \\
-61.4 \\
-51.6 \\
-53.3\end{array}$ & $\begin{array}{r}-51 \\
-43 \\
\end{array}$ & $\begin{array}{l}-53\left(325^{\circ}\right) \\
-44\left(375^{\circ}\right) \\
--\end{array}$ & $\begin{array}{r}10 \\
12 \\
8 \\
6 \\
15\end{array}$ & $\begin{array}{r}11 \\
12 \\
10 \\
6 \\
13\end{array}$ & $\begin{array}{r}{ }^{d} 2.1 \\
2.5 \\
2.2\end{array}$ & $\begin{array}{l}10.8 \\
18.5 \\
14.2 \\
10.0 \\
14.1\end{array}$ & \begin{tabular}{c}
0.95 \\
1.14 \\
\hdashline 1.00
\end{tabular} & $\begin{array}{l}1.03 \\
1.76 \\
1.35 \\
0.95 \\
1.34\end{array}$ & $\begin{array}{l}0.98 \\
2.00 \\
1.35 \\
0.95 \\
1.34\end{array}$ & $\begin{array}{r}1,473 \\
>1,426 \\
\hdashline 2,090\end{array}$ & $\begin{array}{l}3,370 \\
320.9 \\
2,620 \\
1,452 \\
1,480\end{array}$ & $\begin{array}{l}5,900 \\
767 \\
3,700 \\
2,900 \\
2,900\end{array}$ \\
\hline $\begin{array}{l}\mathrm{PbO} \\
\mathrm{Cu}_{2} \mathrm{O}_{2} \\
\mathrm{Ru}_{2} \\
\mathrm{Rh}_{2} \mathrm{O}_{2}\end{array}$ & $\begin{array}{l}52.0 \\
42.5 \\
26.3 \\
21.0\end{array}$ & $\begin{array}{r}16.6 \\
24.1 \\
\end{array}$ & $\begin{array}{r}-44.9 \\
-35.0 \\
\end{array}$ & $\mid-$. & $-42\left(150^{\circ}\right)$ & $\begin{array}{r}18 \\
19 \\
3 \\
4\end{array}$ & $\begin{array}{r}18 \\
19 \\
3 \\
4\end{array}$ & $\begin{array}{r}2.5 \\
2.7 \\
\end{array}$ & $\begin{array}{r}23.5 \\
23.9 \\
9.6\end{array}$ & \begin{tabular}{l}
1.14 \\
1.23 \\
\hdashline
\end{tabular} & $\begin{array}{l}2.24 \\
2.28 \\
0.91\end{array}$ & $\begin{array}{l}2.55 \\
2.80 \\
0.91\end{array}$ & \begin{tabular}{r}
888 \\
1,235 \\
\hdashline-2 \\
$-2-$
\end{tabular} & $\begin{array}{l}327.4 \\
1,083 \\
2,450 \\
1,985\end{array}$ & $\begin{array}{r}1,620 \\
2,300 \\
4,150 \\
>2,500\end{array}$ \\
\hline
\end{tabular}




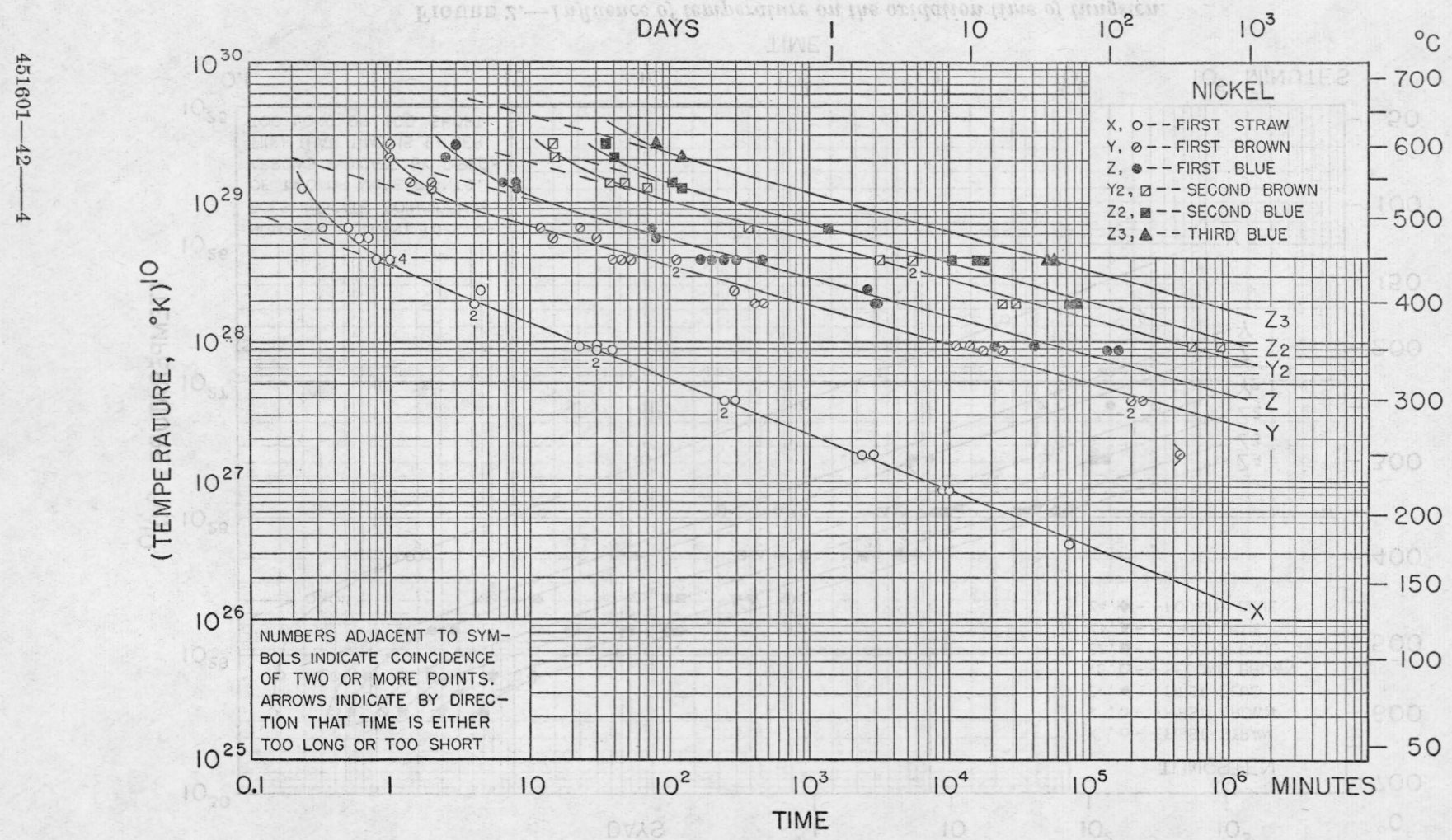

Figdre 1.-Influence of temperature on the oxidation time of nickel. 


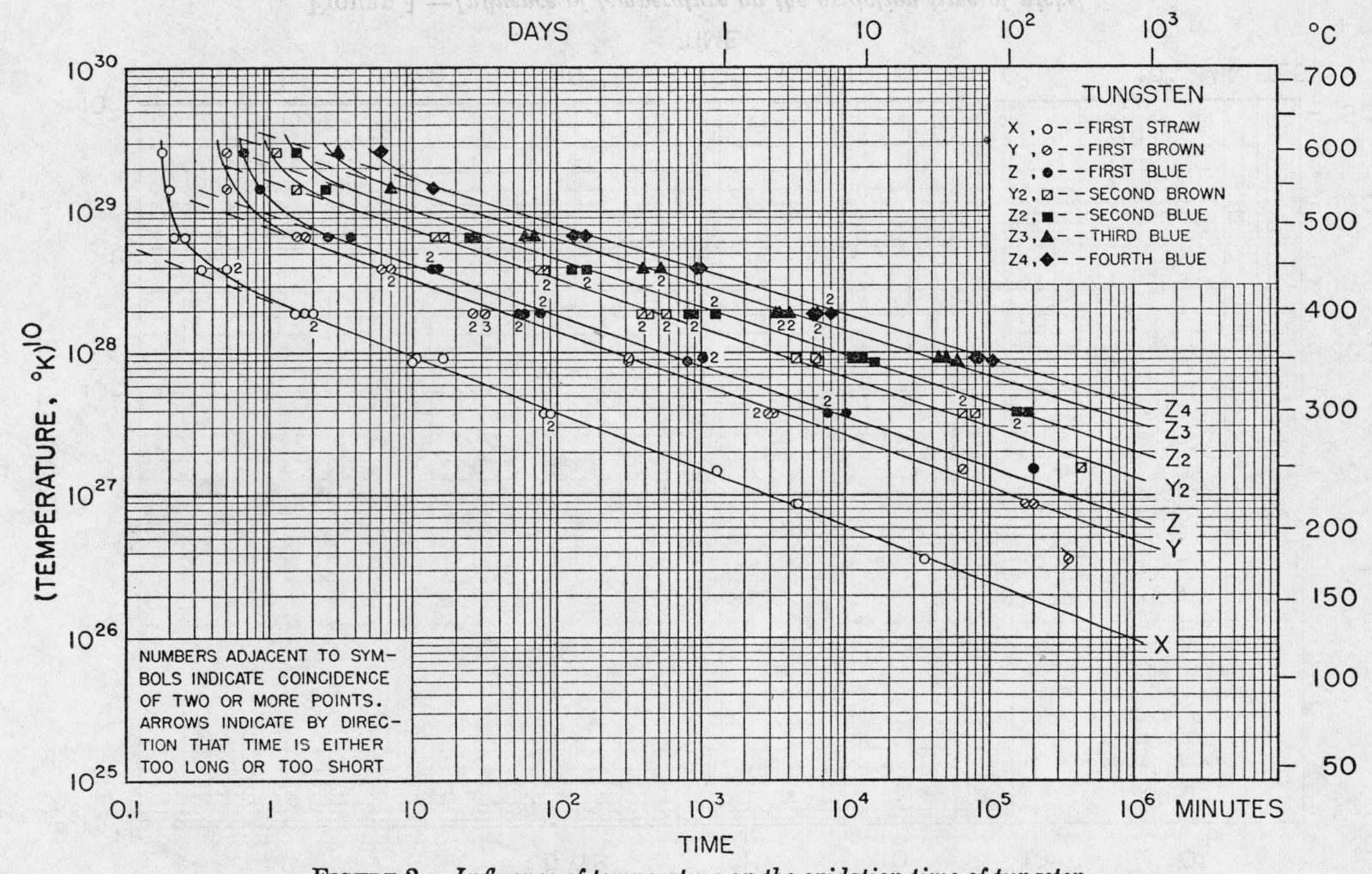

FIGURE 2.-Influence of temperature on the oxidation time of tungsten. 


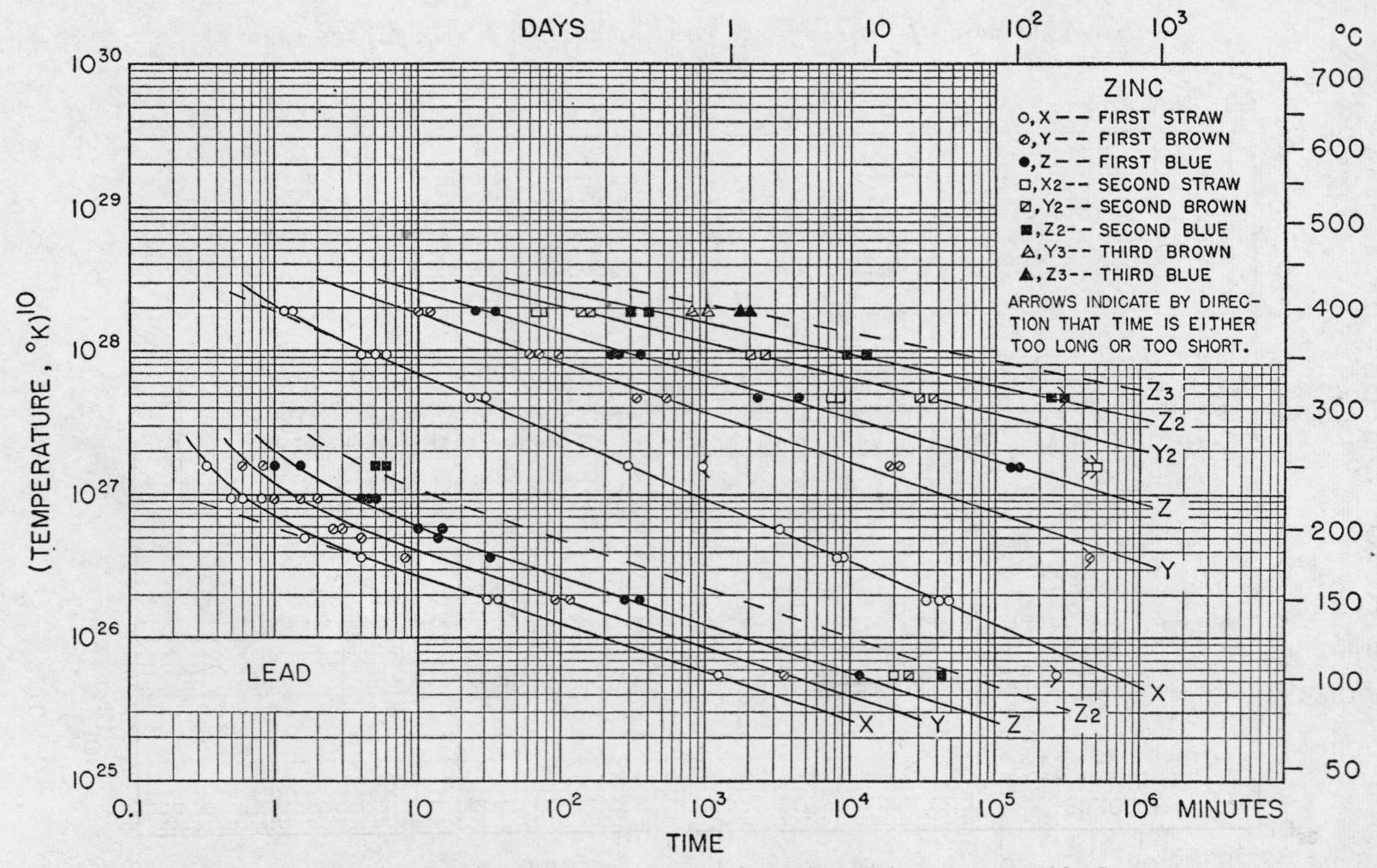

FIGURE 3.-Influence of temperature on the oxidation time of zinc and lead. 


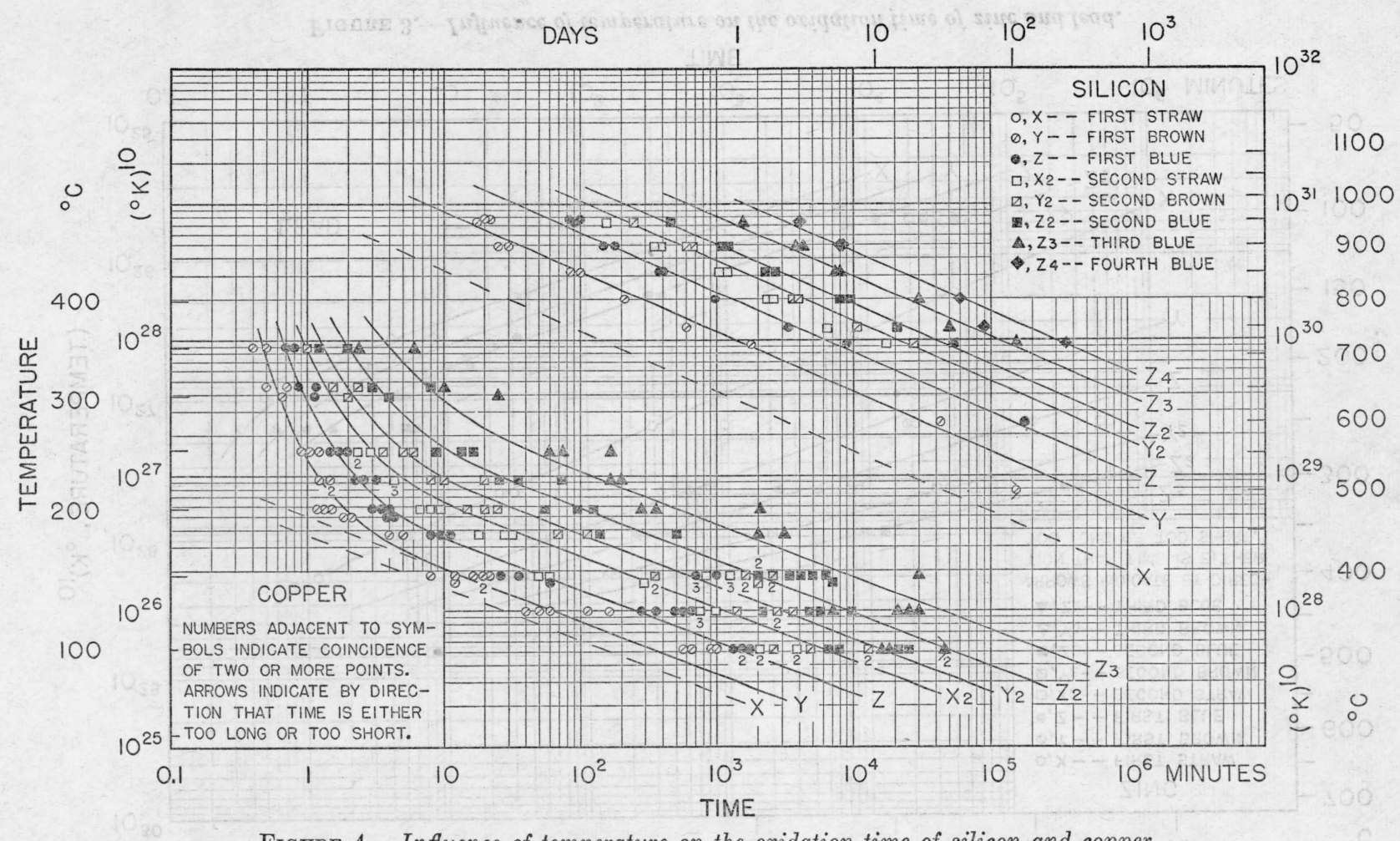

FIgURE 4.-Influence of temperature on the oxidation time of silicon and copper. 


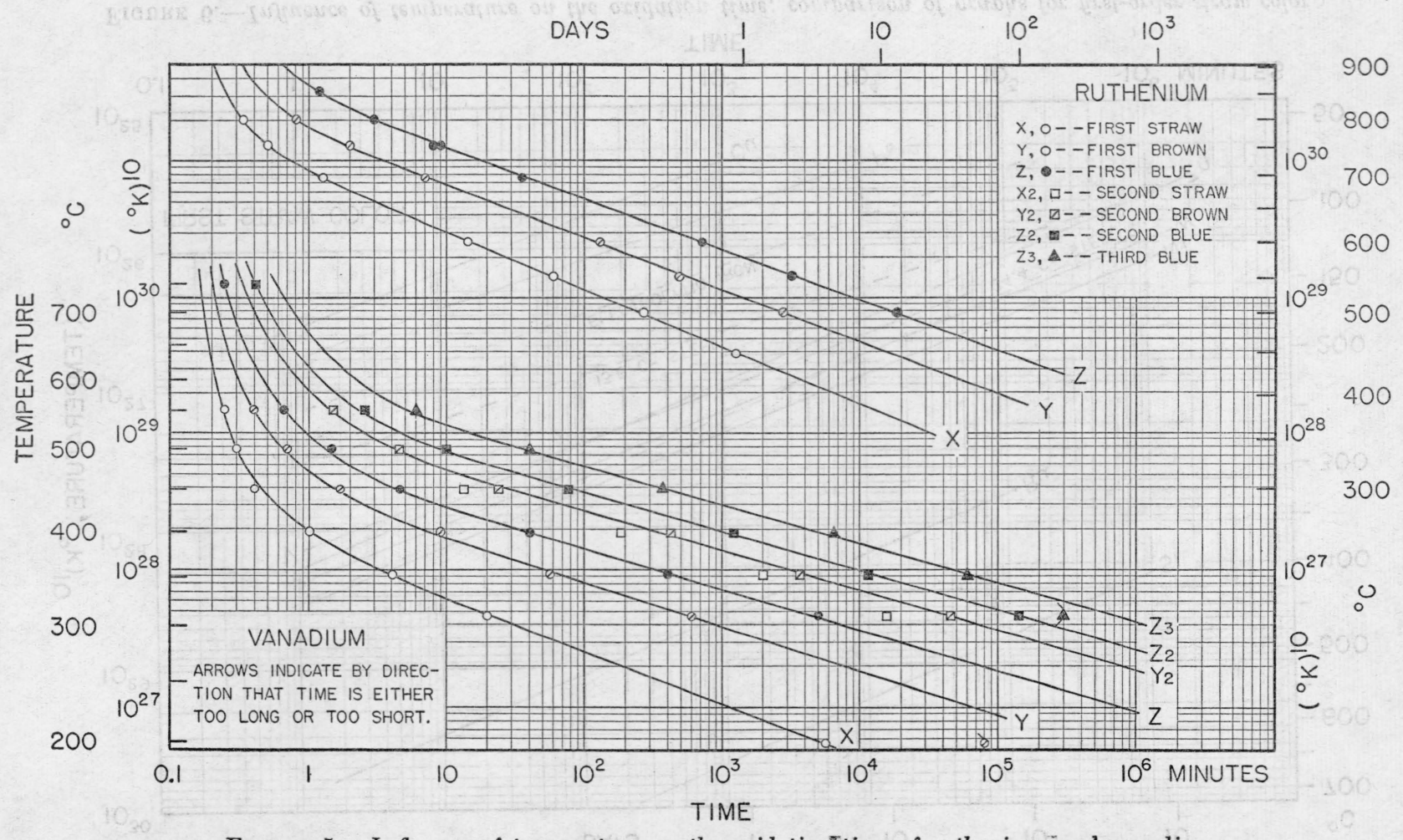

FIGURE 5.-Influence of temperature on the oxidation-time of ruthenium and vanadium. 


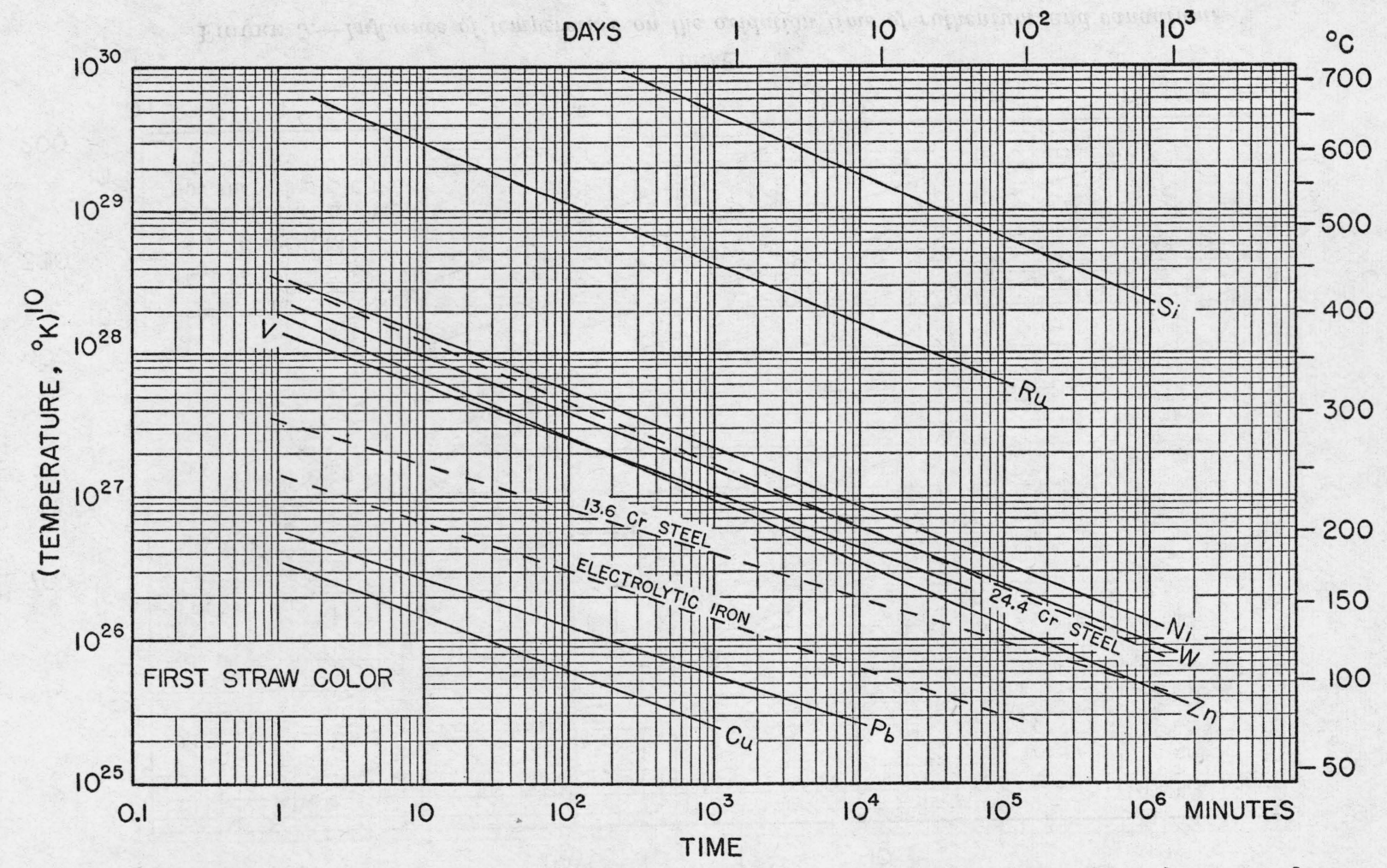

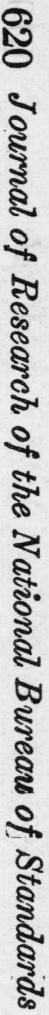

FIGURE 6.-Influence of temperature on the oxidation time; comparison of graphs for first-order straw color. 


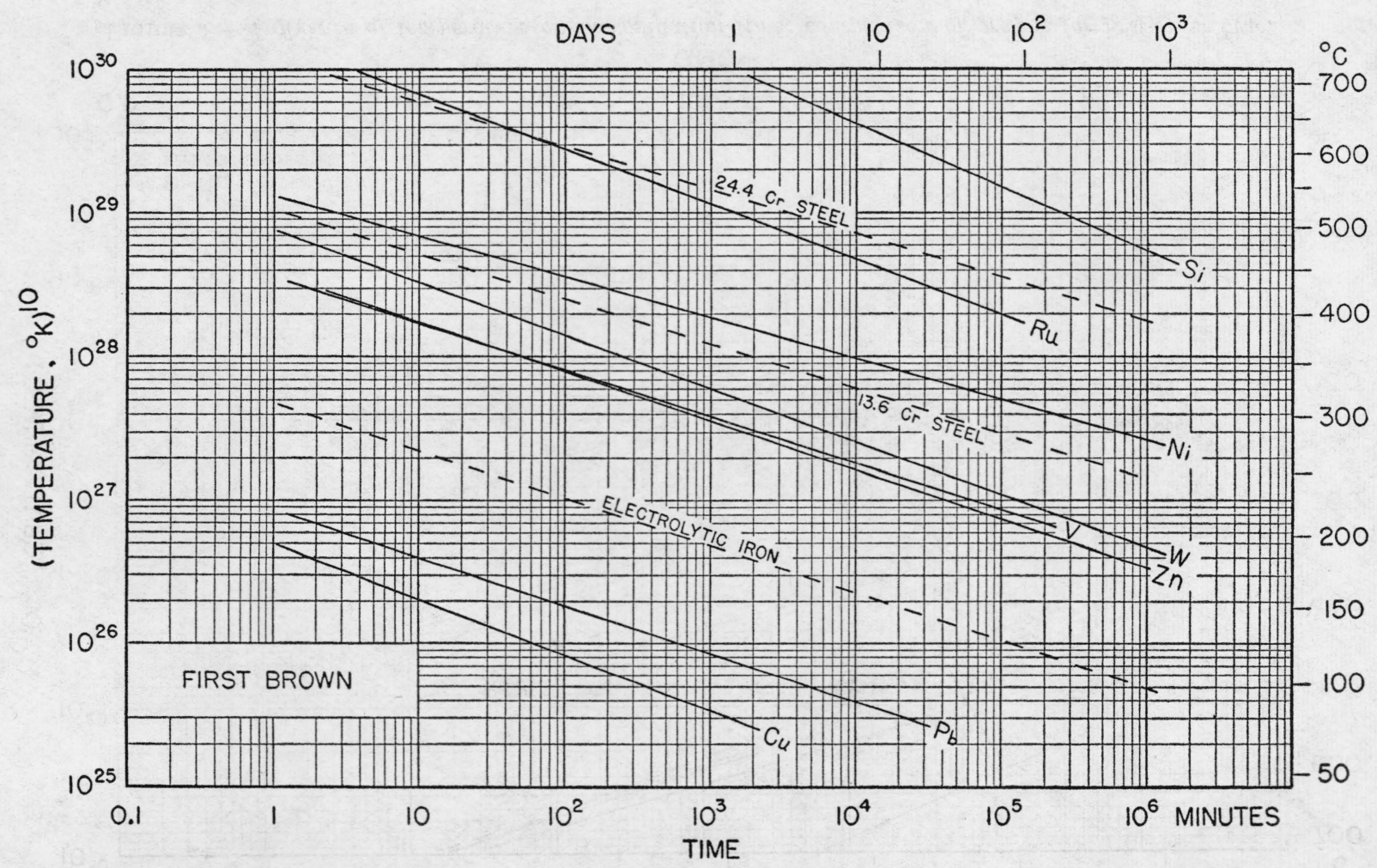

FIGURE 7.-Influence of temperature on the oxidation time; comparison of graphs for first-order brown. 


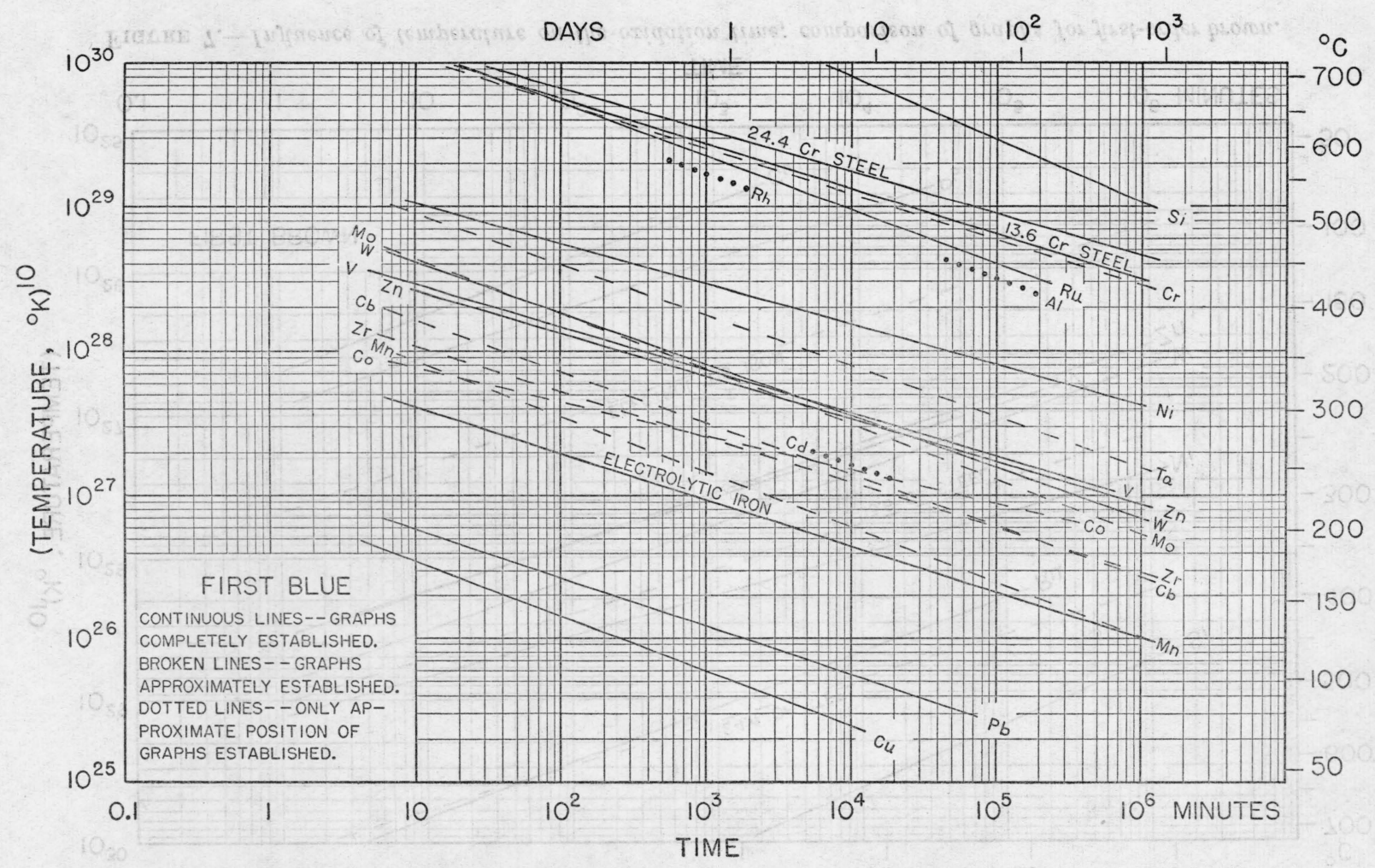

जे

FIGURE 8.-Influence of temperature on the oxidation time; comparison of graphs for first-order blue. 


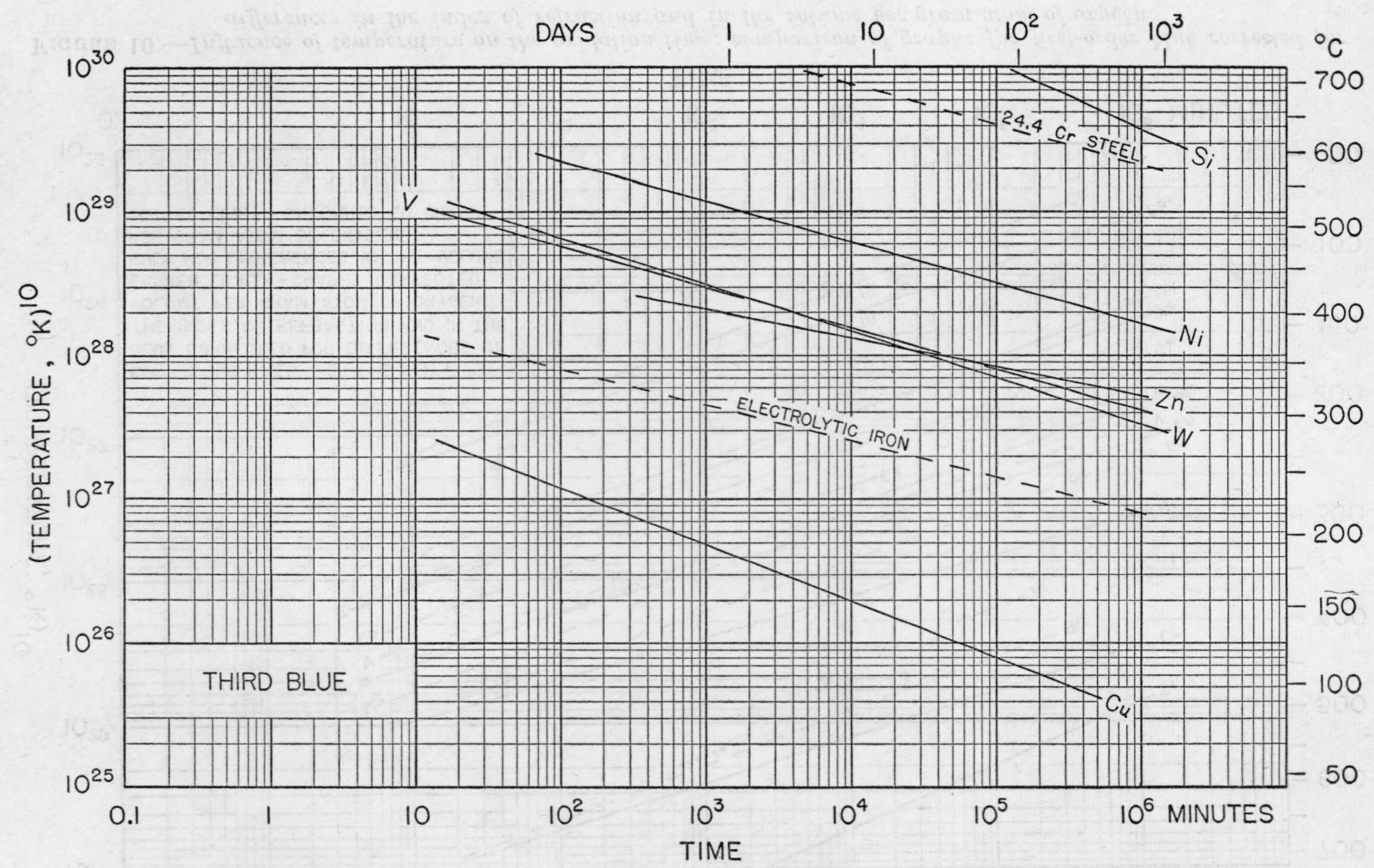

FIGURE 9.-Influence of temperature on the oxidation time; comparison of graphs for third-order blue. 


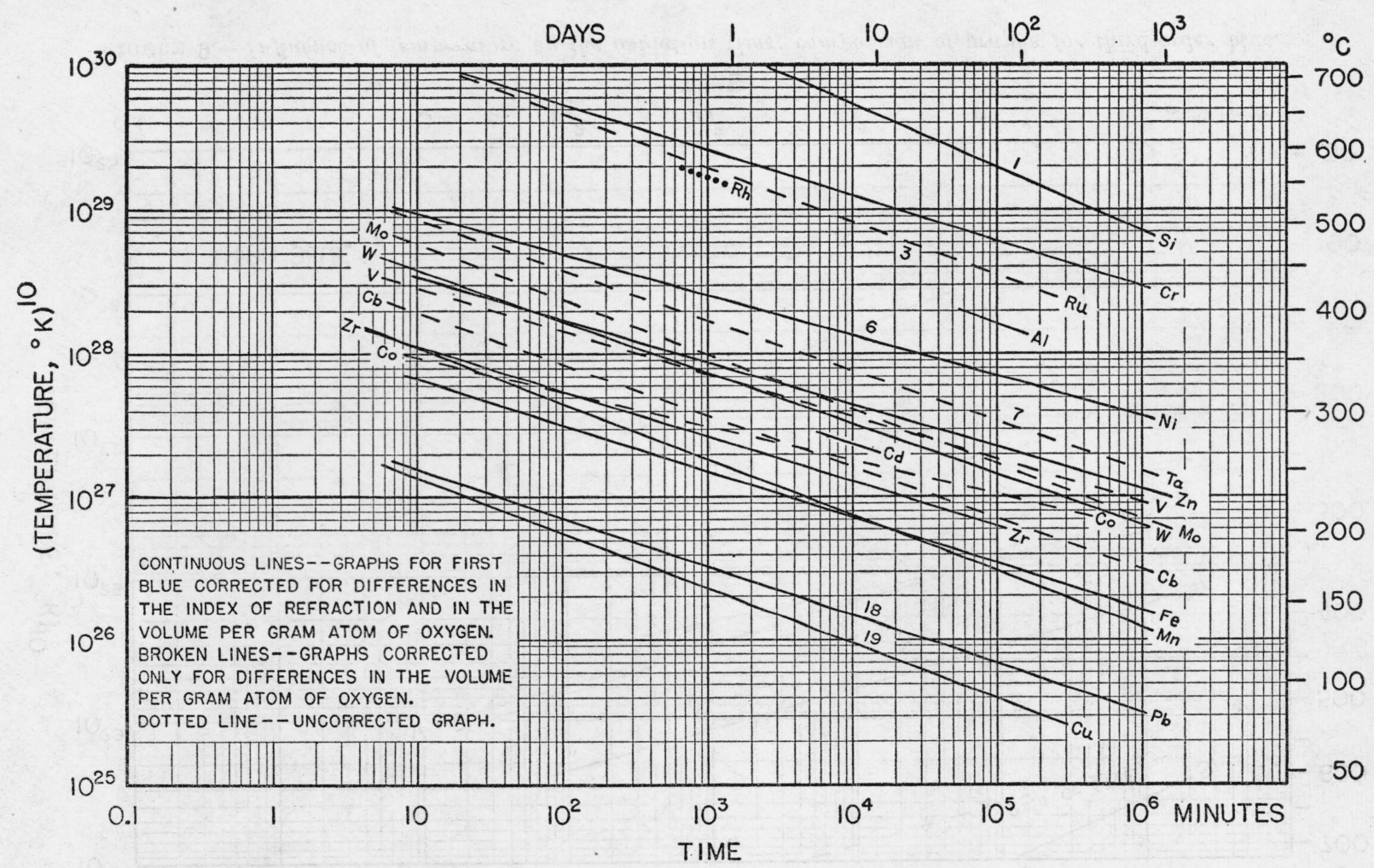

FIGURE 10.-Influence of temperature on the oxidation time; comparison of graphs for first-order blue corrected for differences in the index of refraction and in the volume per gram atom of oxygen. 


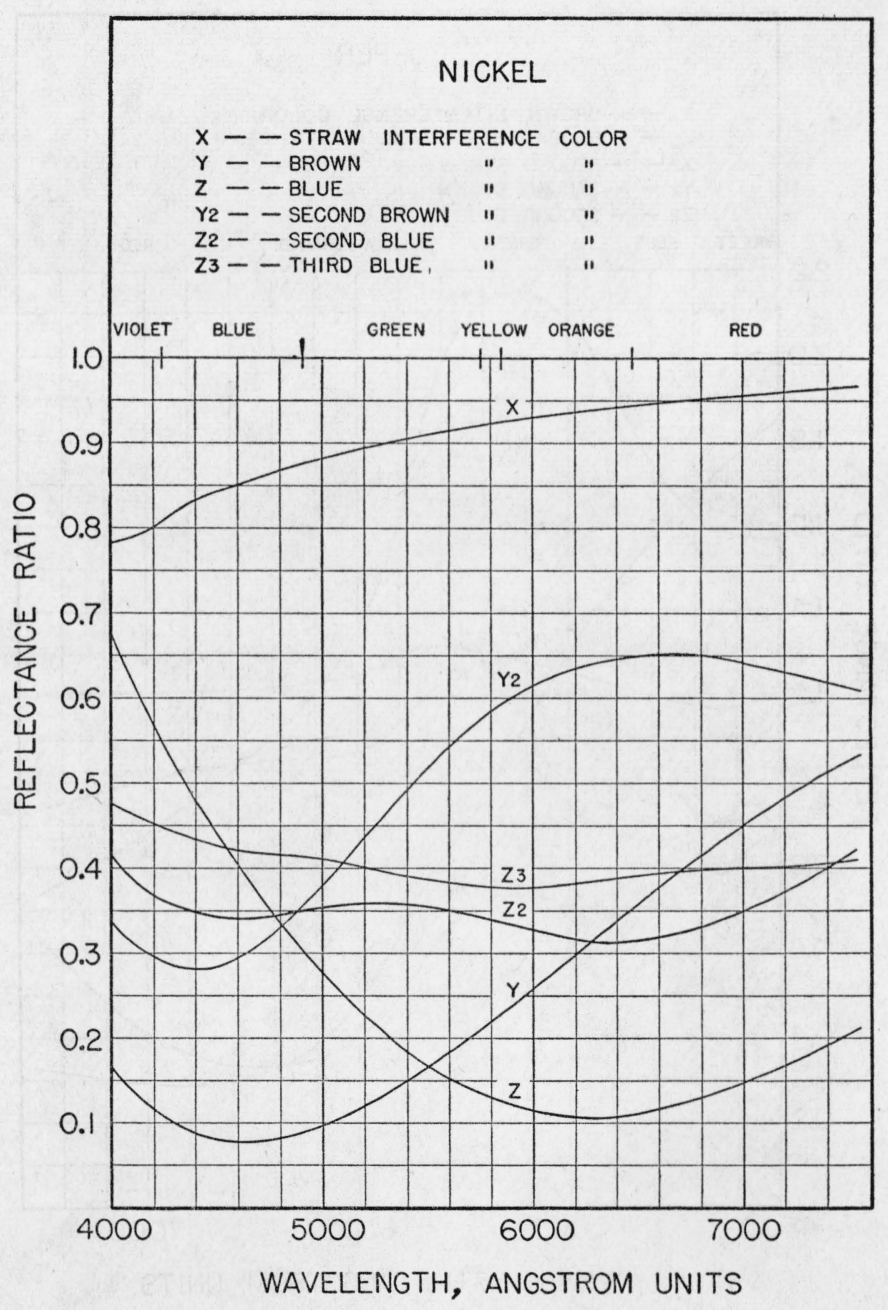

FigURE 11.-Variation of reflectance ratio with wavelength for interference colors on nickel. 


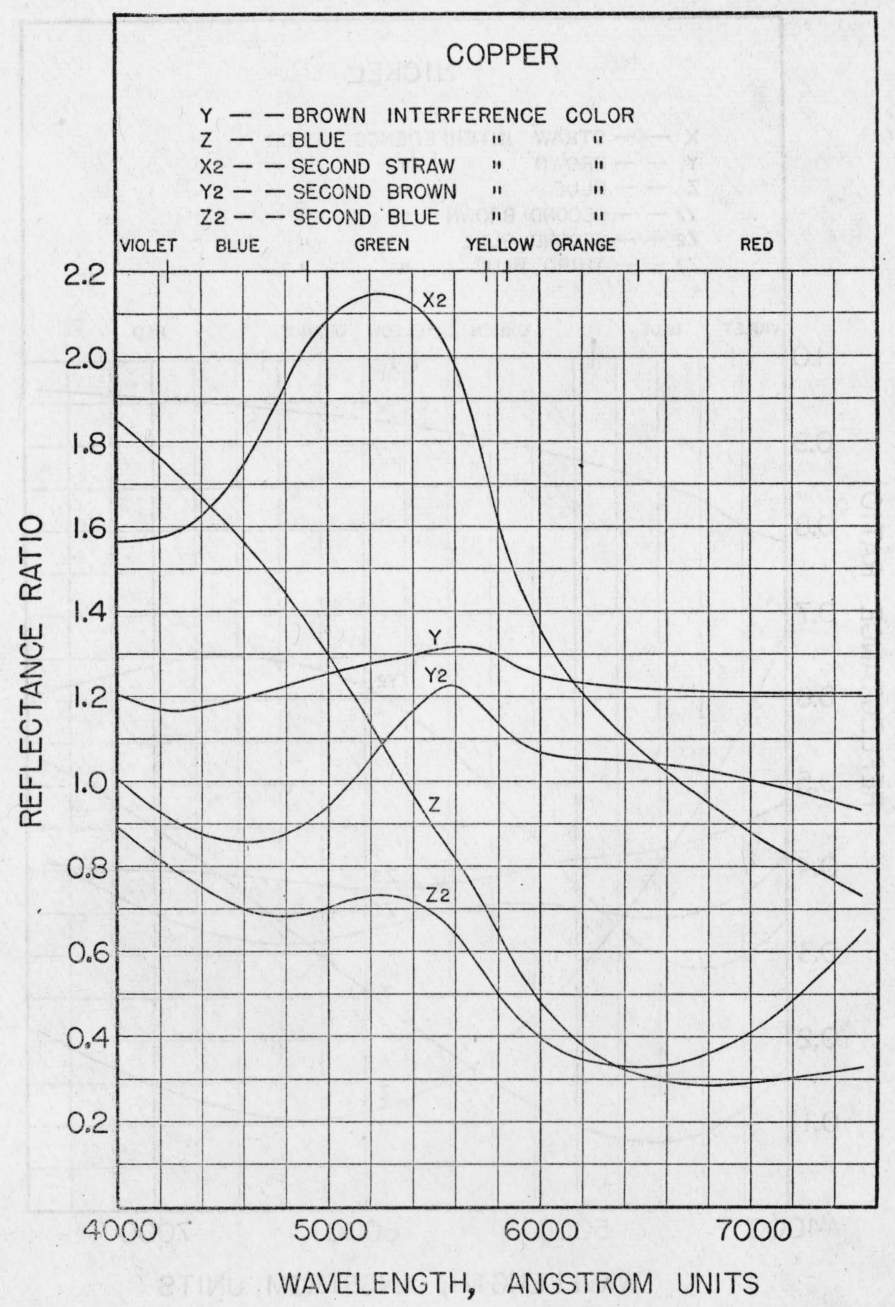

FIGURE 12.-Variation of reflectance ratio with wavelength for interference colors on copper. 


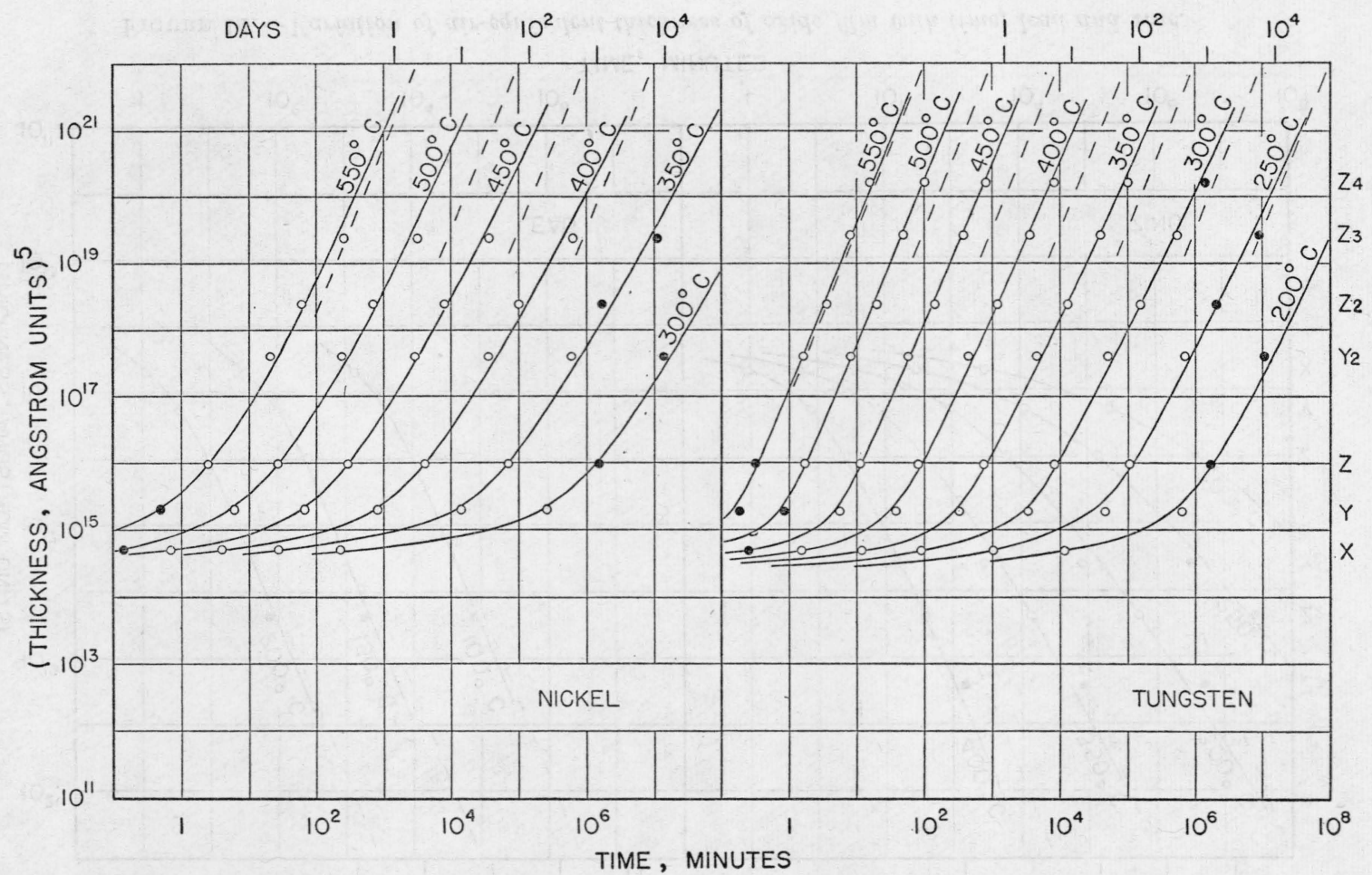

FIGURE 13.-Variation of air-equivalent thickness of oxide film with time; nickel and tungsten. 


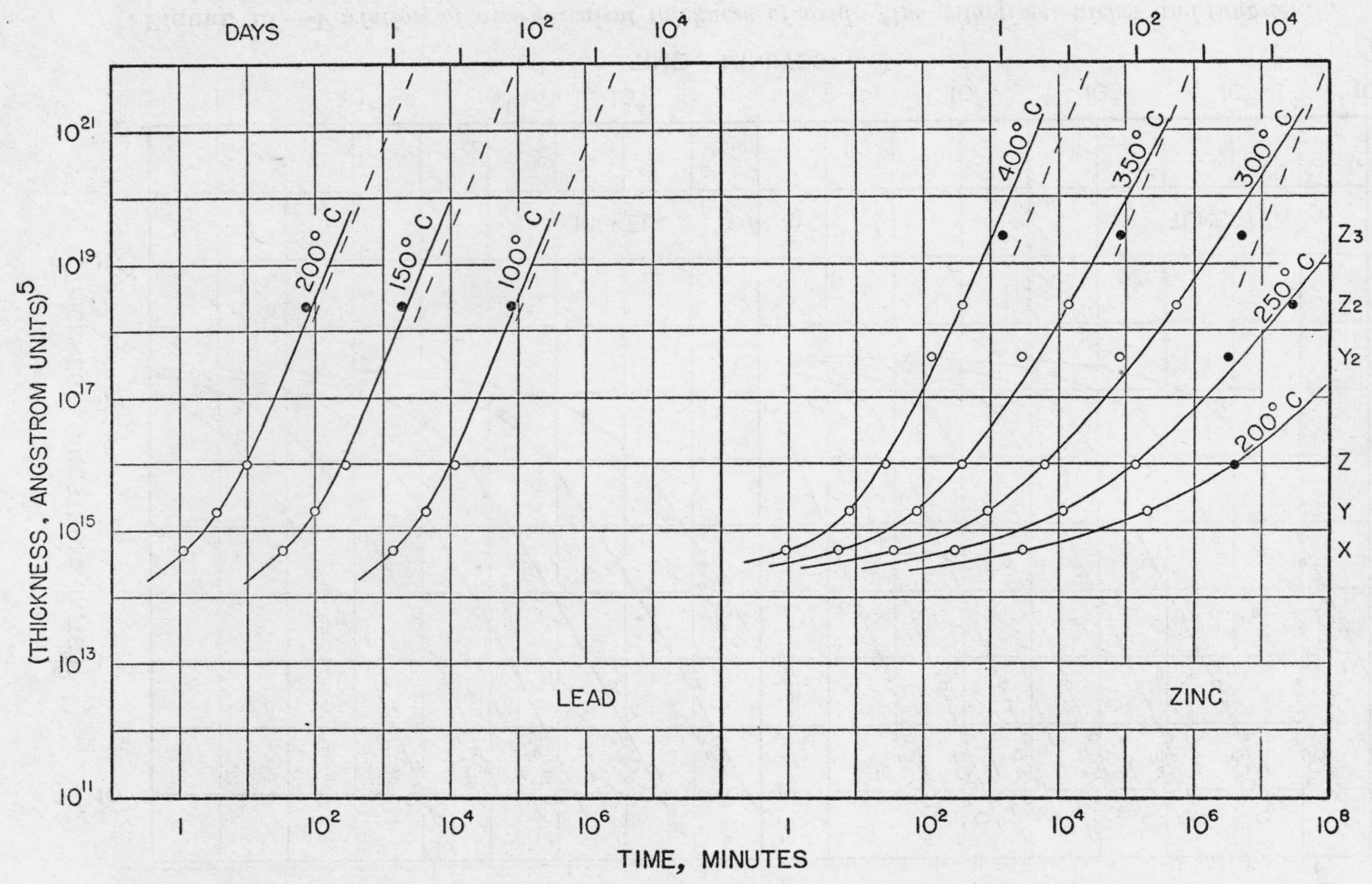

व

FIGURE 14.-Variation of air-equivalent thickness of oxide film with time; lead and zinc. 


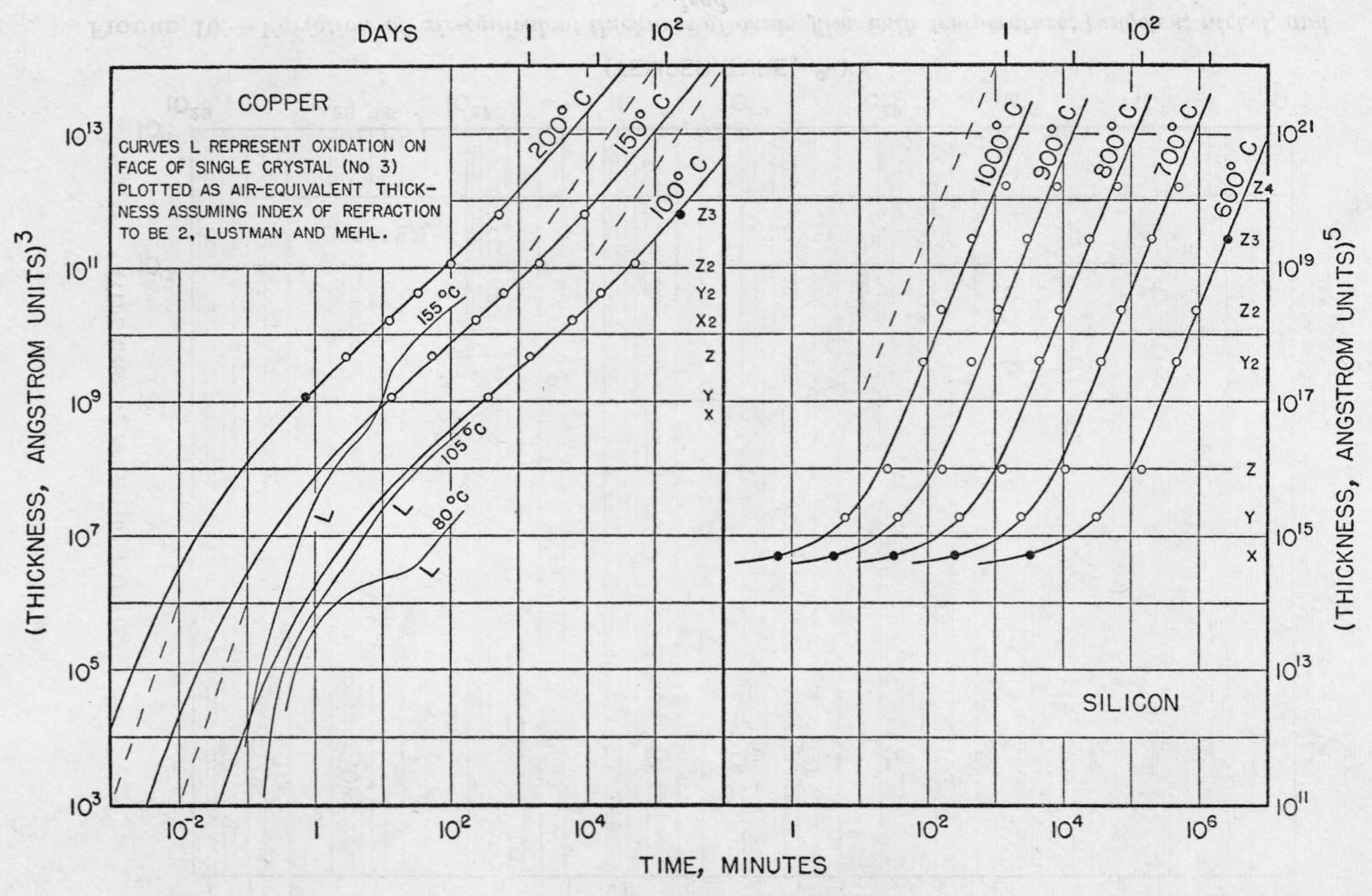

है 


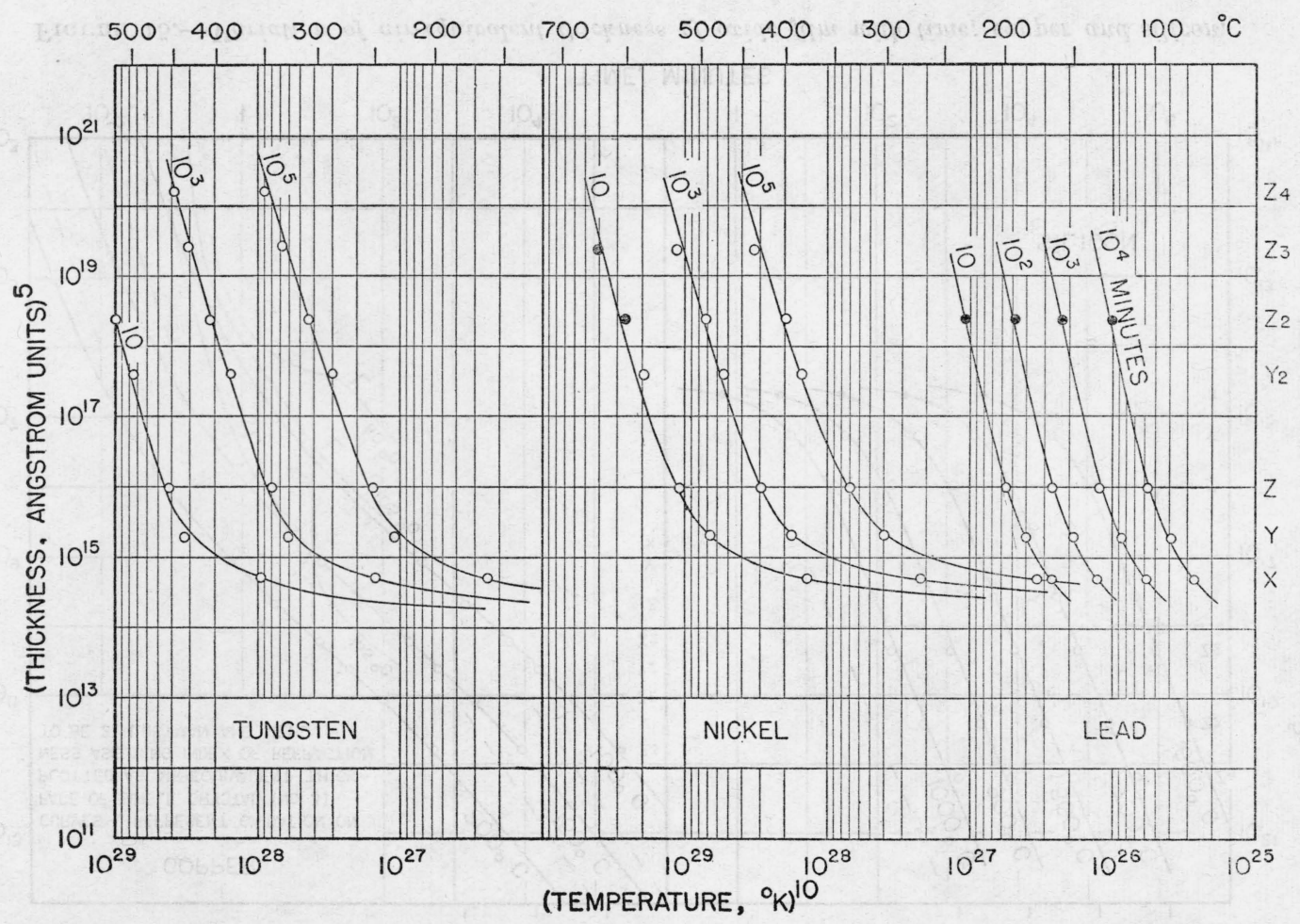

वे

FIgURE 16.-Variation of air-equivalent thickness of oxide film with temperature; tungsten, nickel, and lead. 


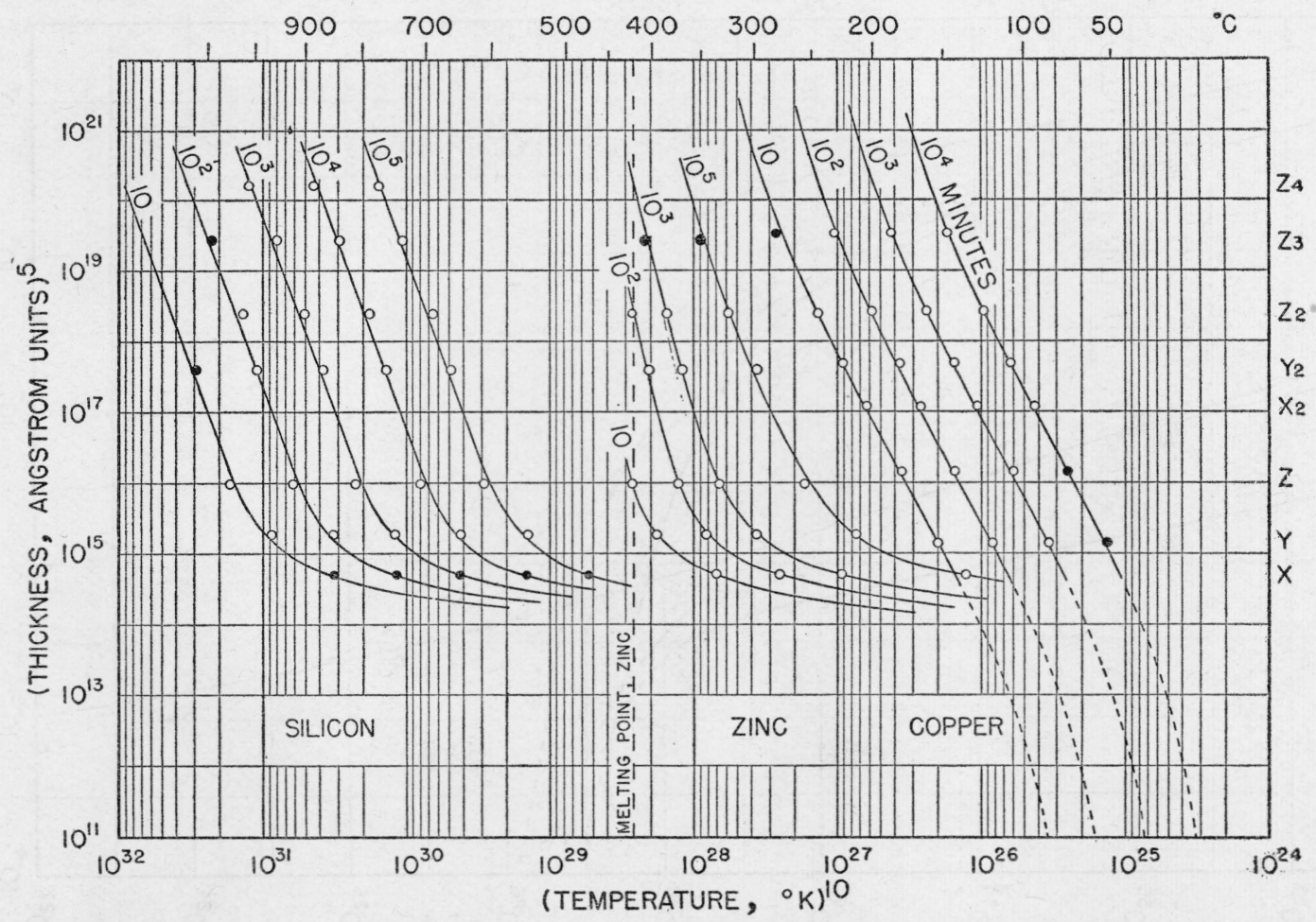


632 Journal of Research of the National Bureau of Standards

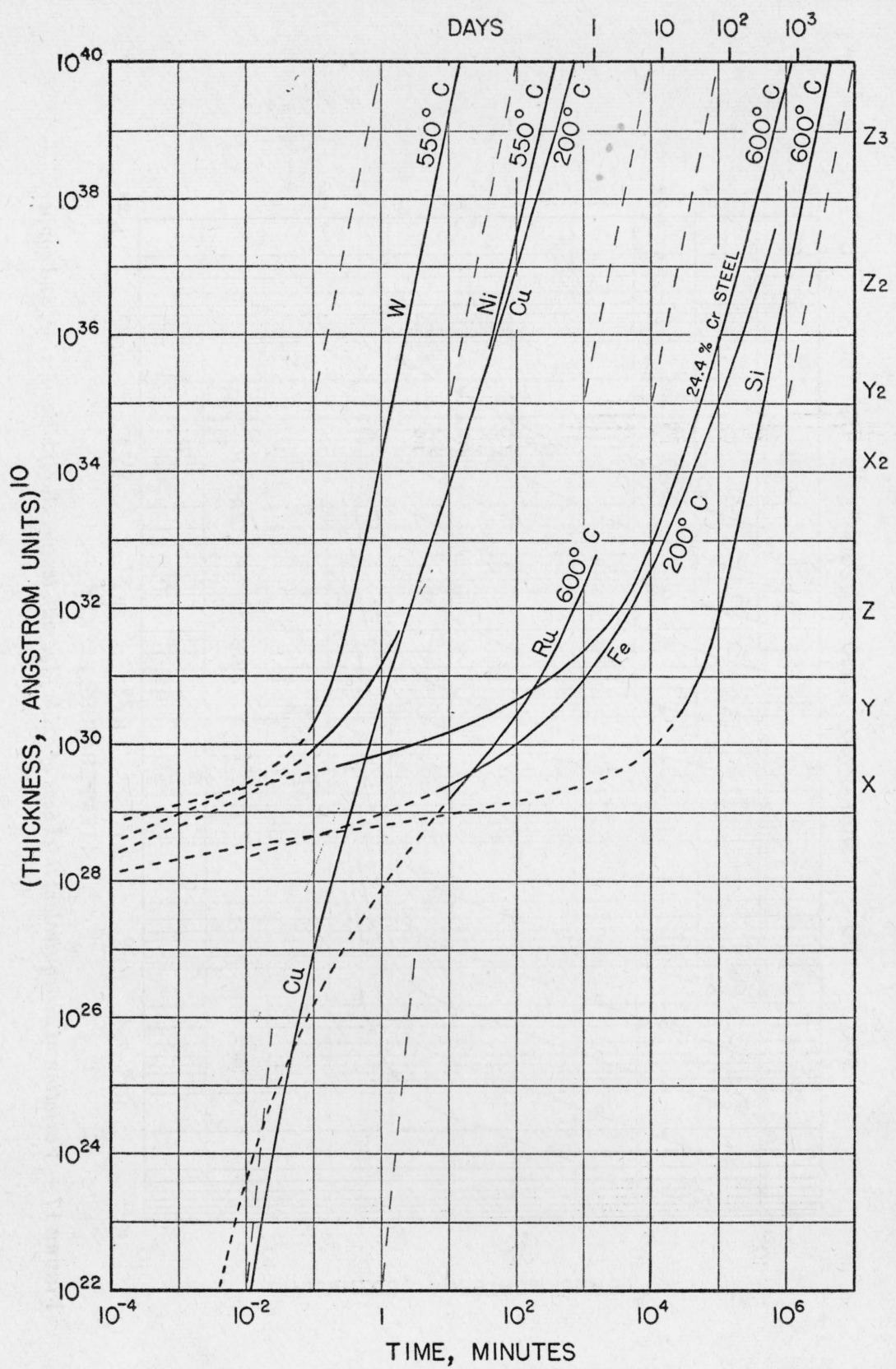

FIGURE 18.-Variation of air-equivalent thickness of oxide film with time; comparison of curves for typical nonferrous metals and steels. 


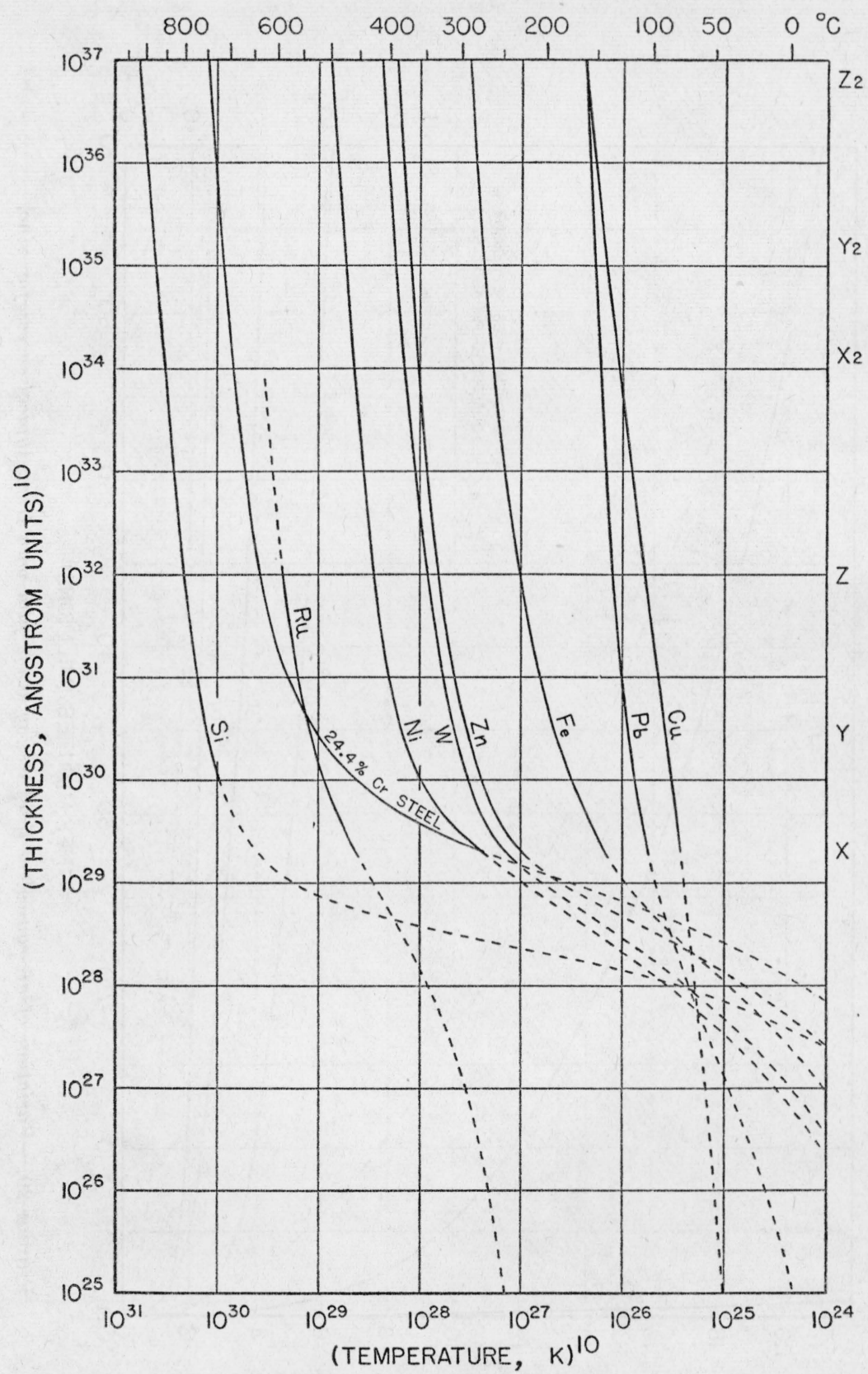

FIGURE 19.-Variation of air-equivalent thickness of oxide film with temperature, for a constant oxidation time of 1,000 minutes; typical nonferrous metals and steels. 


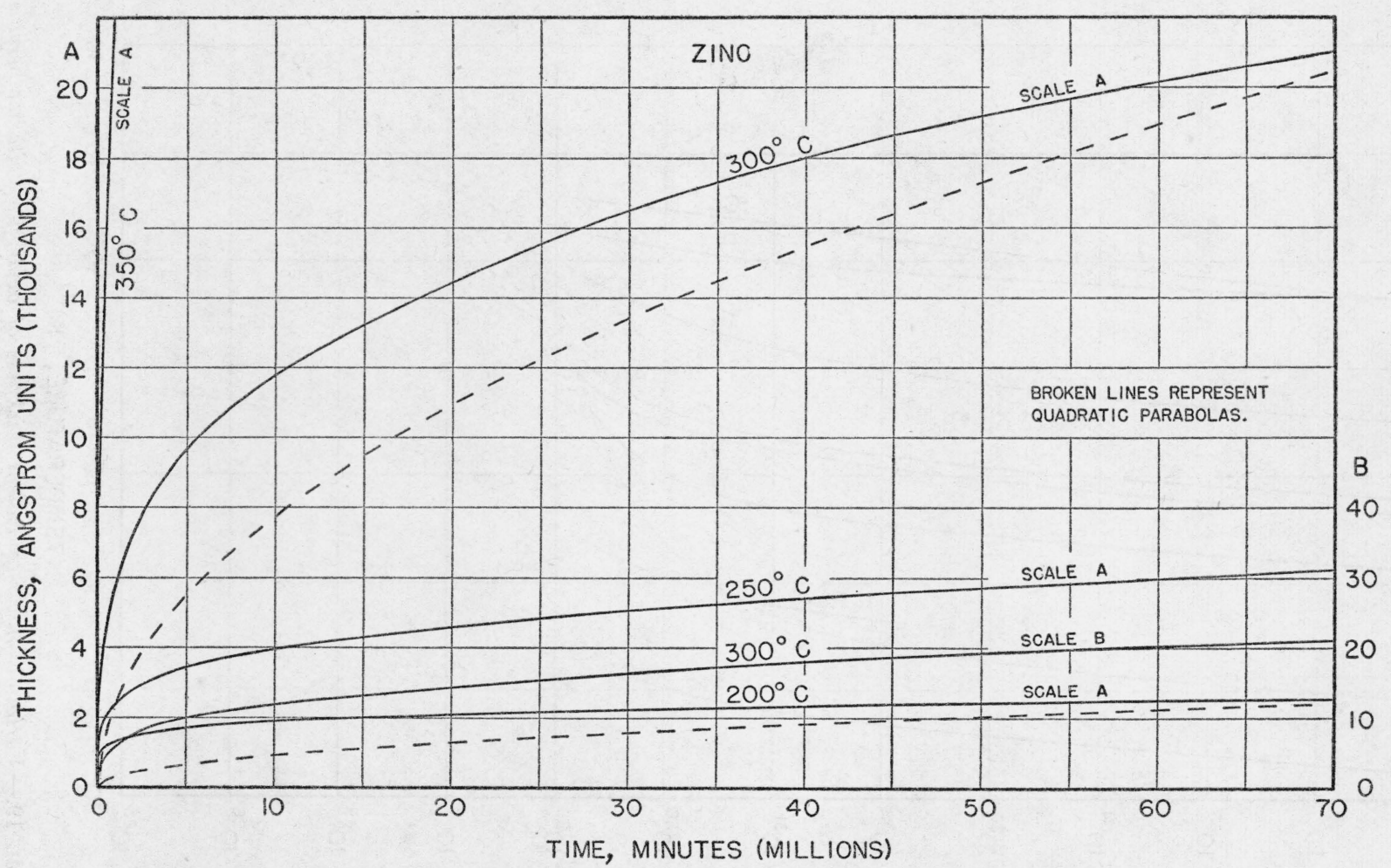

שิ

FIGURe 20.-Variation of air-equivalent thickness of oxide film with time; typical curves for zinc. 


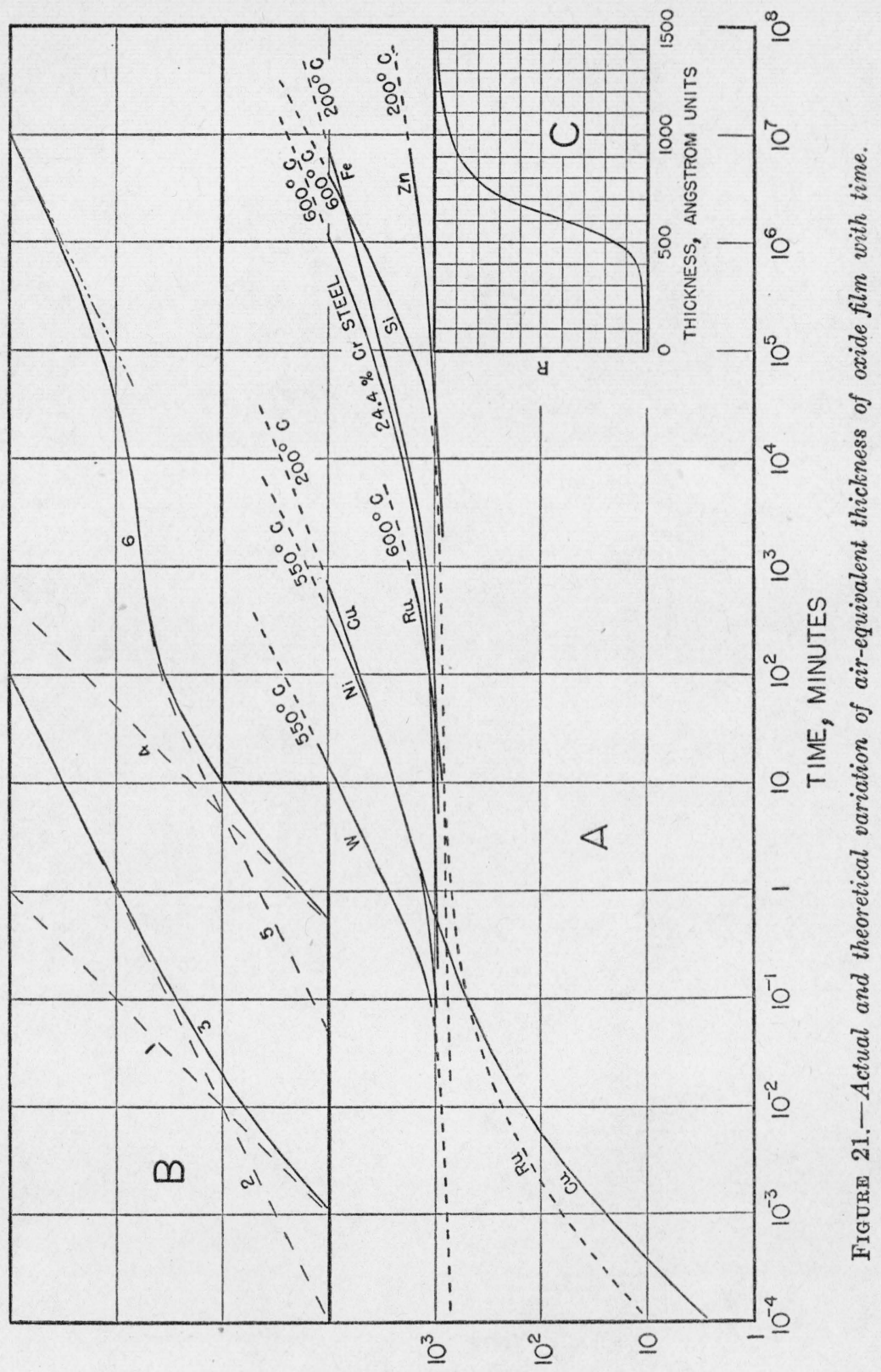

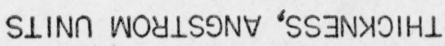

Washington, February 17, 1942. 